\title{
CONSIDERAZIONI SULL'AFFINITÁ ED ORIGINE DELLA FLORA PTERIDOLOGICA DELLA REGIONE MEDITERRANEA
}

\author{
Rodolfo E. G. PICHI SERMOLLI, FMLS.
}

SUMMARY: First of all, this research deals with the delimitation of the Mediterranean Region, which is circumscribed in a narrow sense. The species and subspecies of pteridophytes recorded within its limits amount to 124 . They belong to 38 genera and to 23 families and represent barely $0.88 \%$ of all the extant Pteridophyta. Thus, the pteridoflora of the Mediterranean Region must be regarded as a poor flora. Starting from the above mentioned data, the research has been extended to the level of ploidy and geographical distribution of each species and subspecies (Table I). The number of diploids is clearly higher than that of the polyploids and on the basis of this ratio the pteridoflora has to be considered as a very ancient one.The geographical distribution of the species and subspecies of the Mediterranean Region, in the adjoining territories and other parts of the world shows that the Mediterranean pteridoflora has its greatest affinity with the flora of the Submediterranean, Atlantic and Asiatic regions.

A brief outline of the most important palaeogeographical events in the Mediterranean area, and some palaeoclimatic notes precede the part dealing with the origin of the Mediterranean pteridoflora. This is mainly based on the chorological and epiontological study of the most significant species of past and present times, of their ancestors and allies. Particular attention is also paid to the tracks of migration followed by some species to reach the Mediterranean area from their first centres of origin in Asia and Africa (Fig. 5). The most ancient of these species, such as Woodwardia radicans, Culcita macrocarpa and Selaginella balansae presumably represent the relicts of a late Cretaceous flora. Others are the relicts of the tropical flora of the Paleogene and mainly of the subtropical laurel flora of the Oligocene. Other species reached the Mediterranean area from the eastern Euroasiatic lands during the Messinian and still others from the northern countries during the pleistocenic glaciations. Finally a rather consistent group of pteridophytes is indigenous to the Mediterranean Region. According to some authors the laurel flora of Oligocene, mentioned above, had its origin in the Canary Islands, but in the author's opinion the more reliable hypothesis is that the oligocenic laurel flora and vegetation originated in the western Mediterranean area and later transmigrated to the Canary Islands, where they survived up to the present time. This hypothesis is supported by recent geological and palaeogeographical research according to which the eastern islands of Canary Archipelago did not emerged from the sea earlier than the Miocene when the laurisilvae had already been widely represented in the Mediterranean area for several milion years. Furthermore, according to some geologists, the eastern Canary Islands are interpreted as a microcontinent or a sialic continental fragment detached from the western margin of northern Africa. Its existence would explain in the best manner the transmigration from Africa to the Canary Islands of both the laurisilvae and the ratite birds whose fossil eggshells have been found in the calcarenites of Miocene-Pliocene in Lanzarote Island.

A picture of the history of the Mediterranean pteridoflora in the light of the palaeogeographical and palaeoclimatic events is briefly outlined as a conclusion of the paper.

Key words: Mediterranean, Pteridoflora, Affinity, Origin. 
RESUMEN: En primer lugar, esta investigación trata acerca de la delimitación de la Región Mediterránea, la cual es considerada en este trabajo circunscrita en sentido estricto. Las especies y subespecies de los pteridófitos señaladas dentro de sus límites suman 124. Éstas pertenecen a 38 géneros y 23 familias y representan aproximadamente el $0.88 \%$ de todos los pteridófitos vivientes. Por lo tanto, la pteridoflora de la Región Mediterránea debe considerarse una flora pobre. En base a los datos antes mencionados, la investigación ha sido ampliada al nivel de ploidía y a la distribución geográfica de cada una de las especie y subespecies (Tab. 1). El número de diploides es indudablemente más alto que el número de los poliploides y teniendo en cuenta esta razón la pteridoflora ha de ser considerada muy antigua. La distribución geográfica de las especies y subespecies de la Región Mediterránea, en los territorios próximos y otras partes del mundo, muestra que la pteridoflora mediterránea tiene su mayor afinidad con la flora de las regiones submediterráneas, atlánticas y asiáticas.

Un esquema de los eventos paleogeográficos más importantes en el área mediterránea y algunas notas paleoclimáticas, preceden la parte que trata acerca del orígen de la pteridoflora mediterránea. Ésta está basada principalmente en el estudio corológico y epiontológico de las especies más significativas de los tiempos remotos y presentes, de sus antepasados y afines. Una especial atención es dedicada también a las vias de emigración seguidas por algunas especies para alcanzar el área mediterránea partiendo de sus primeros centros de orígen en Asia y Africa (Fig. 5). Las más antiguas de dichas especies, como Woodwardia radicans, Culcita macrocarpa y Selaginella balansae, representan presumiblemente los relictos de una antigua flora cretácea. Otros son los relictos de la flora tropical del Paleogeno y principalmente de la lauriflora subtropical del Oligoceno. Otras especies han penetrado en el área mediterránea a partir de los países euroasiáticos orientales durante el Messieniense y otras aún de los países nórdicos durante las glaciaciones pleistocénicas. Finalmente otro consistente grupo de pteridófitos es endémico de la Región Mediterránea. Según algunos autores, la lauriflora del Oligoceno antes mencionada tuvo su origen en las Islas Canarias, sin embargo, según la opinión del autor la hipótesis más atendible es la que sostiene que la lauriflora oligocénica, al igual que la vegetación, tuvieron su origen en el área Mediterránea occidental y transmigraron más tarde a las Islas Canarias en donde sobrevivieron hasta el tiempo actual. Esta hipótesis es avalada por las recientes investigaciones geológicas y paleogeográficas, según las cuales, las islas orientales del archipiélago de las Canarias emergieron del mar no antes del Mioceno, cuando ya, desde varios millones de años antes, las laurisilvas cubrían una amplia extensión del área mediterránea. Por lo demás, según algunos geólogos, las Islas Canarias orientales se deben interpretar como un microcontinente o como un fragmento continental siálico separado del márgen occidental norte-africano. Su existencia explicaría de la mejor manera la transmigración de Africa a las Islas Canarias, de las laurisilvas lo mismo que los ratites, cuyas cáscaras fósiles de huevos fueron hallados en las calcarenitas del Mioceno-Plioceno de la Isla de Lanzarote.

Por último, se delinea brevemente un cuadro de la historia de la pteridoflora mediterránea a la luz de los eventos paleogeográficos y paleoclimáticos.

Palabras clave: Mediterráneo, Pteridoflora, Afinidad, Origen.

In occasione della Seconda Riunione dell'OPTIMA (Organization for the Phyto-Taxonomic Investigation of the Mediterranean Area), svoltasi a Firenze nel Maggio 1977, mi fu richiesto di tenere una relazione sulle Pteridophyta della Regione Mediterranea, che fu pubblicata due anni più tardi negli Atti della Riunione con il titolo «A survey of the pteridological flora of the Mediterranean Region» (Pichi Sermolli 1979).

A distanza di oltre un decennio, mi è sembrato interessante riprendere un argomento che fu in parte oggetto della mia relazione ed esporre alcune considerazioni 
sull'affinità ed origine della flora pteridologica della Regione Mediterranea alla luce del notevole progresso compiuto in questo tempo dalla pteridologia, prevalentemente nel campo della citotassonomia, citogenetica, palinologia e corologia.

Prima ancora di presentare un elenco della flora pteridologica di cui ci dobbiamo occupare, ritengo sia necessario stabilire i limiti della Regione Mediterranea. E' questo un problema a lungo dibattuto, ma tuttora aperto.

Alcuni studiosi, ad esempio Meusel $(1943,1962)$ e Meusel, Jäger e Weinert (1965), delimitano la Regione Mediterranea in senso assai ampio, fino al punto da includere in essa anche la Macaronesia. Rikli (1942-48) circoscrive la Regione Mediterranea in maniera molto ampia, e pure escludendo la Macaronesia include in essa le Regioni Submediterranea e Pontica, e l'intera Africa settentrionale. Assai ampiamente è intesa l'area mediterranea anche nella Med-Checklist (Greuter et al. 1984) nella quale, senza stabilirne i limiti, vengono trattate le piante vascolari che crescono nell'intero territorio, nei suoi confini politici, di ogni paese bagnato dal Mare Mediterraneo, oltre al Portogallo, Bulgaria, Crimea e Giordania. Tuttavia viene apertamente riconosciuto che molte piante ivi elencate ben poco o nulla hanno a che fare con la flora mediterranea. Assai meno ampiamente la Regione Mediterranea viene circoscritta da Good (1953) e Mattick (1964), i quali tuttavia includono in essa, a mio avviso ingiustificatamente, una vasta porzione dell'Africa settentrionale arida. Più stretti sono i limiti assegnati alla regione da Takhtajan (1986); ma non ritengo giustificato includere in essa gli Appennini, la Tripolitania nord-occidentale, l'intera Tunisia, l'Algeria settentrionale e tutto il Marocco. Va notato comunque che i confini descritti nel testo (p. 119) non del tutto corrispondono a quelli delineati nella carta pubblicata nella sua opera. Meglio stabiliti appaiono i confini dell'Africa mediterranea rispetto alla Regione Saharo-Arabica tracciati da Quézel (1978).

Altri studiosi invece, tra i quali mi piace ricordare Kleopov (1972), hanno circoscritto la Regione Mediterranea in modo più limitato. Anche nella «Carte bioclimatique de la zone méditerranéenne» (Emberger et al. 1963) e nella «Carte de la Végetation de la région mediterranéenne» (Lalande et al. 1969), sebbene non riguardanti la flora, la Regione Mediterranea è limitata ad una fascia, in generale non molto ampia ed a tratti interrotta, che circonda il Mediterraneo, escludendo da essa le grandi catene montuose che dall'Europa media si protendono verso sud, come pure le zone aride africane ed asiatiche. Non molto diversamente la Regione Mediterranea fu da me intesa anni addietro, in base allo studio della sua flora pteridologica (Pichi Sermolli 1979) e come tale, salvo lievi ritocchi, viene da me delimitata ancor oggi (Fig. 1), rafforzato nella mia opinione dai dati desunti dalla «Vegetation map of Africa» (White et al. 1983), dai resultati emersi dal recente studio biogeografico della pteridoflora iberica (Pichi Sermolli et al. 1988), dalle indicazioni e carte pubblicate in vari lavori sulla flora di alcuni territori che si affacciano sul Mediterraneo, tra i quali desidero ricordare quelli di Zohary (1962) per la Palestina, Israele e Giordania, di Davis (1965) e Parris e Fraser-Jenkins (1980) per la Turchia, e dalle osservazioni personali fatte durante varie ricerche pteridologiche condotte in alcuni paesi dell'Europa meridionale ed in Africa settentrionale. 
Tutte le specie e sottospecie di Pteridophyta che crescono spontaneamente nella Regione Mediterranea, come sopra delimitata, sono elencate nella Tabella I. L'elenco, corredato dei nomi degli autori di ogni singola entità, rappresenta in definitiva una «checklist» della pteridoflora mediterranea. Da esso sono tuttavia escluse tutte le entità avventizie, quelle volutamente od involontariamente introdotte dall'uomo, quelle coltivate o sfuggite alla coltura ed inoltre quelle naturalizzate, anche se da un tempo assai lungo.

Per quanto riguarda la circoscrizione ed ordinamento tassonomico delle famiglie e generi mi sono attenuto, salvo poche eccezioni, al «Tentamen Pteridophytorum genera in taxonomicum ordinem redigendi» da me pubblicato alcuni anni orsono (Pichi Sermolli 1977). Per le specie e sottospecie mi sono basato su varie flore, monografie o revisioni di particolari famiglie o generi, come pure su ricerche personali bibliografiche e di erbario. Famiglie, generi, specie e sottospecie sono elencati in ordine tassonomico. Di regola ho tralasciato di tener conto delle varietà, ma ho preferito citare anche la varietà in quei casi (due in tutto) in cui la sottospecie comprende più varietà delle quali una soltanto, quella citata, è rappresentata nella Regione Mediterranea.

L'elenco suddetto rappresenta la base essenziale per la ricerca che mi sono proposto. Innanzi tutto esso consente di fare alcune considerazioni sulla consistenza numerica e tassonomica della pteridoflora della Regione Mediterranea.

In base a questo elenco risulta infatti che essa consta di 124 entità tra specie e sottospecie, appartenenti a 38 generi e 23 famiglie. Pur tenendo presente che le terre della Regione Mediterranea, quale è qui circoscritta, coprono un'estensione in definitiva assai ridotta, constatiamo che il numero delle specie e sottospecie ivi presenti è abbastanza esiguo. Di fatto esso corrisponde ad appena lo $0.88 \%$ del totale delle pteridofite viventi, stimato in 14.000 unità tra specie e sottospecie. Pertanto la pteridoflora della Regione Mediterranea va considerata una flora povera.

Passando ad esaminare le famiglie presenti nella Regione Mediterranea, ciò che colpisce di più è l'assenza delle Lycopodiaceae, tanto più che esse sono rappresentate in territori limitrofi dell'Europa e Macaronesia. La loro assenza è difficile a spiegare, mentre la mancanza delle Grammitaceae, Actiniopteridaceae, Elaphoglossaceae e Nephrolepidaceae, oggi presenti nella Macaronesia, trova forse una spiegazione nelle attitudini tropicali delle specie di queste famiglie anche se non escludo che alcune di esse vivessero in tempi remoti nella Regione Mediterranea. Abbastanza logica appare invece l'assenza delle Cryptogrammaceae, Onocleaceae e Woodsiaceae, rappresentate nelle regioni limitrofe europee da specie boreali.

Molte altre considerazioni potrebbero essere fatte in base ai dati numerici ricavati dal suddetto elenco, ma rimando per esse a quanto fu detto nel mio lavoro pubblicato anni addietro (Pichi Sermolli 1979) ed a quello più recente sul valore 


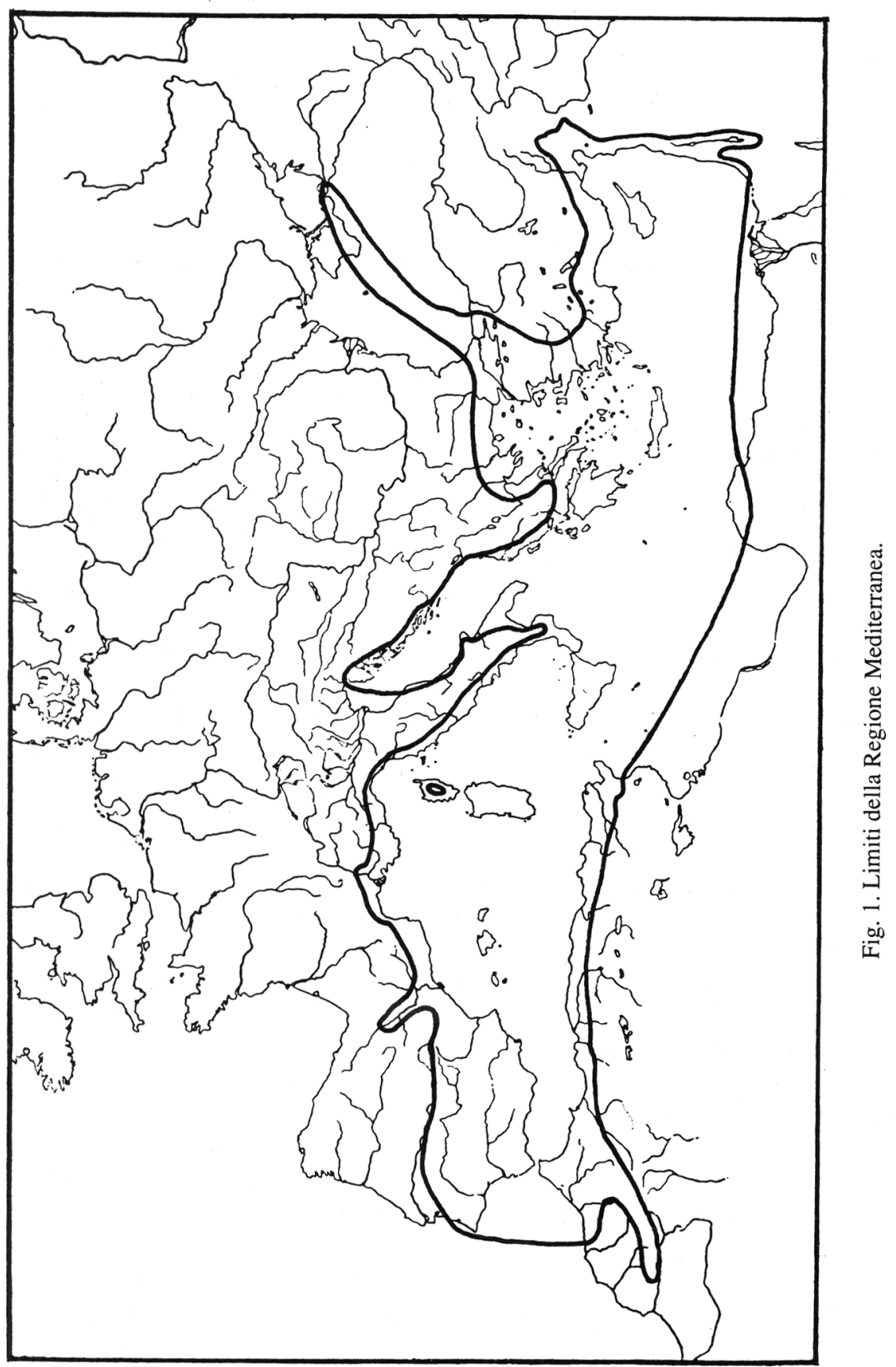


biogeografico della pteridoflora iberica (Pichi Sermolli et al. 1988). Tuttavia, tale elenco, sebbene indispensabile come punto di partenza, non è sufficiente a conseguire lo scopo principale di questa ricerca che mira ad accertare l'affinità della pteridoflora mediterranea e per quanto possibile ipotizzare la sua origine. Pertanto ho esteso la mia indagine allo studio dell'areale, numero cromosomico ed altri dati citologici di ciascuna specie e sottospecie comprese nell'elenco suddetto. I resultati della mia indagine sono riassunti nella Tabella I nella quale, oltre all'elenco, vengono forniti per ogni singola entità due tipi diversi di dati: citologici e corologici.

I dati citologici riguardano innanzi tutto il livello di ploidia, stabilito tenendo presente il numero base $(x)$ del genere cui l'entità appartiene. Tengo a precisare che il numero $x$ da me considerato corrisponde al numero gametico più basso $(n)$ effettivamente riscontrato in una o più specie di un determinato genere e non il numero ricavato matematicamente dividendo l'effettivo numero base per 2,3,4,6, etc., al fine di ottenere un numero più basso di quello ricavato dal conteggio cromosomico, possibilmente un numero primo o comunque un numero molto basso. Sono messe così in evidenza le entità diploidi $(2 x)$ e tetraploidi $(4 x)$ ed eventualmente quelle triploidi $(3 x)$, esaploidi $(6 x)$, ottoploidi $(8 x)$,etc. Per alcune entità sono noti più di un numero $x$. Per queste entità sarebbe stata mia intenzione citare il solo numero od i numeri riscontrati in esemplari provenienti dalla Regione Mediterranea, ma purtroppo i conteggi a me noti riguardano in massima parte campioni di altre regioni. Pertanto sono stato costretto a citare nella tabella quasi tutti i numeri $x$ a me noti. Per quanto riguarda il tipo di ploidia dei poliploidi nessuna particolare indicazione viene riportata per gli allotetraploidi accertati o presunti, mentre è aggiunta la sigla $A u$ per le entità ritenute autopoliploidi. Altro dato preso in considerazione nella tabella concerne il modo di procreazione. La maggior parte delle entità hanno un tipo di riproduzione sessuale e nessun particolare segno è usato per esse, ma la sigla $A p$ è usata per le specie apomittiche.

I dati relativi alla distribuzione geografica delle specie e sottospecie riguardano in primo luogo la distribuzione in seno alla Regione Mediterranea, che è stata suddivisa in tre settori: orientale, occidentale e meridionale, rispettivamente indicati nella tabella con le sigle E,W,S. Come confine tra settore orientale ed occidentale ho preso una linea che divide al centro l'Adriatico ed oltrepassato il canale di Otranto si dirige in linea retta fino a Tripoli. La suddivisione dell'area mediterranea nei tre suddetti settori, senza riconoscerne, contro il parere di taluni studiosi, uno centrale, mi è sembrata più naturale ed appare anche giustificata da un punto di vista paleogeografico. Quanto al settore meridionale esso riguarda essenzialmente le terre dell'Africa settentrionale in gran parte bagnate dal Mare Mediterraneo ed in minor grado dall'Oceano Atlantico.

La distribuzione geografica delle specie e sottospecie è indicata in 14 colonne di cui la prima è riservata alla Regione Mediterranea (RM) nel suo insieme, con indicazione delle entità endemiche contrassegnate con la lettera minuscola $e$. Va precisato che ho considerato come tali quelle entità che vivono allo stato spontaneo soltanto in particolari zone, di solito assai limitate, della Regione Mediterranea. Nella 
stessa colonna ho indicato con $r$ le entità che sono da interpretare come relitti di flore precedenti sopravvissuti alle mutate condizioni ambientali in speciali zone di rifugio.

Nelle rimanenti colonne (2-14) viene riportata con una croce (+) la presenza delle specie e sottospecie della Regione Mediterranea, nei territori limitrofi ed in altre parti del mondo. Nel mio precedente lavoro sulla pteridoflora mediterranea (Pichi Sermolli 1979) misi in evidenza la distribuzione geografica delle specie e sottospecie della Regione Mediterranea nei paesi limitrofi indicando per questi ultimi le Regioni floristiche circostanti (Euro-siberiana, Irano-turaniana, Saharo-arabica, e Macaronesica) alle quali la loro flora viene per lo più assegnata. In questo lavoro, anziché fare riferimento alle Regioni floristiche ho preferito indicare la presenza delle varie entità nei territori limitrofi caratterizzati da determinate condizioni ambientali.

Mi è sembrato che un confronto di questo genere fosse più concreto, più aderente alla realtà, di quello basato sulle Regioni floristiche che riflettono concetti più astratti e soggettivi. Ho così riconosciuto le seguenti zone (corrispondenti alle colonne 1-14) contrassegnate con le sigle a fianco indicate per ciascuna di esse:

1 - Regione Mediterranea (RM)

2 - Europa Atlantica (EuA)

3 - Zona submediterranea, centroeuropea e pontico-sudsibirica (Eu)

4 - Asia occidentale: Anatolia, Caucasia ed Iran settentrionale (WAs)

5 - Zone aride nordafricane ed asiatiche (ZA)

6 - Macaronesia (Mac)

7 - Africa tropicale (AfT)

8 - Africa australe (AfA)

9 - Asia (excl. Asia occidentale e mediterranea) e Malesia (AsM)

10 - Australia $(\mathrm{Au})$

11 - Nuova Zelanda (NZ)

12 - Nordamerica (NAm)

13 - Centroamerica (CAm)

14 - Sudamerica (SAm)

In aggiunta ai dati forniti nella tabella, desidero ricordare che Pteris vittata, Pteris cretica ed Adiantum capillus-veneris sono presenti anche in alcune isole dell'Oceania.

Un esame della Tabella I ci offre lo spunto per varie considerazioni sulla costituzione, affinità ed origine della flora pteridologica della Regione Mediterranea.

Le informazioni citologiche sono raramente prese in considerazione nei lavori riguardanti la corologia e l'epiontologia, ma mio avviso esse ci sono di grande aiuto non soltanto per individuare luoghi e tempi di origine di determinate entità, come ebbi modo di mostrare nella mia relazione al precedente Simposio di Botanica Crittogamica a Madrid nel 1987 (Pichi Sermolli 1990), ma anche nel valutare il significato e l'età di alcuni endemismi, nel mettere in risalto la presenza di vicarianti, come pure nel confermare la maggiore o minore antichità del popolamento vegetale di una data regione.

Per quanto mi consta, Hagerup (1932) fu tra i primi ad ipotizzare l'esistenza di una correlazione tra il numero dei poliploidi ed il clima, ecologia e distribuzione 


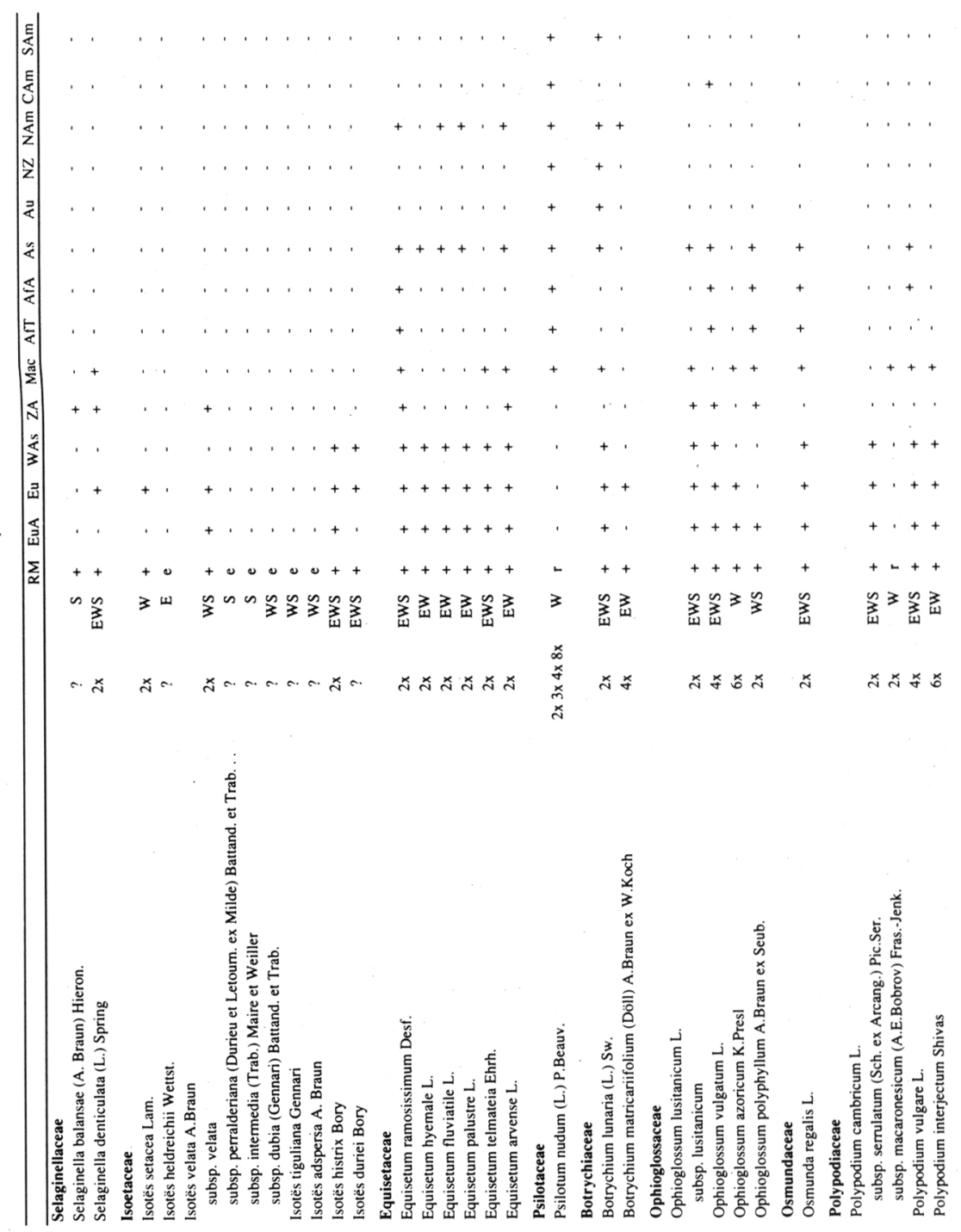




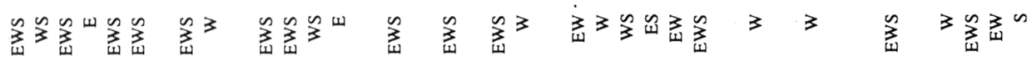

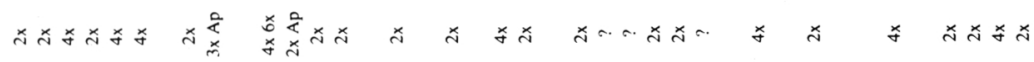

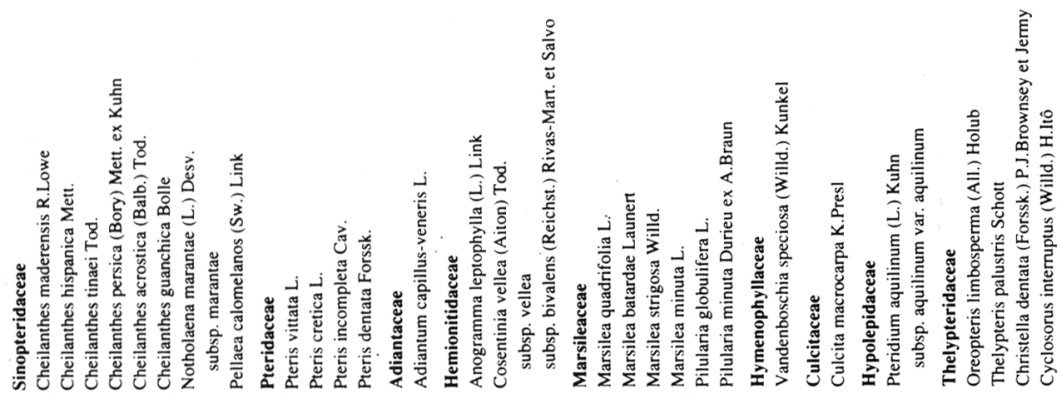




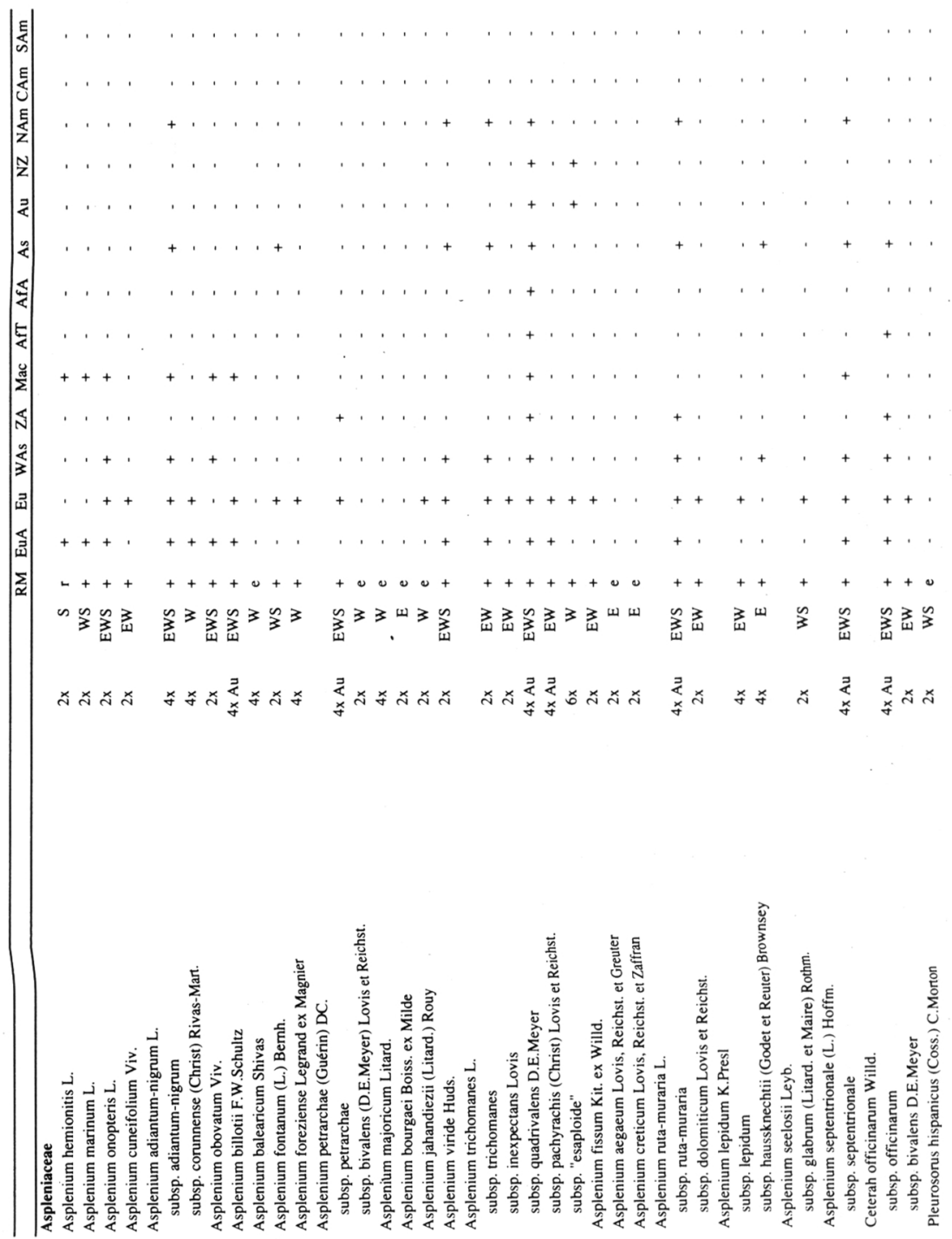




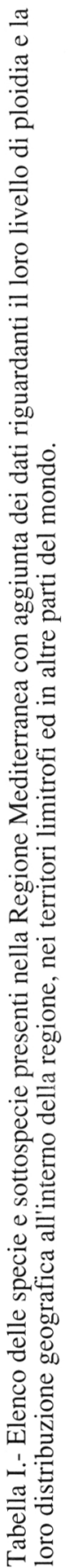


geografica. Tischler (1935) approfondì questo tipo di ricerche giungendo alla conclusione che nei paesi settentrionali la percentuale dei poliploidi rispetto ai diploidi è più alta che nei paesi meridionali. Più tardi A. e D. Löve (1943, 1948) studiando le Angiosperme di vari paesi posti a latitudini diverse, misero in evidenza statisticamente che la percentuale dei poliploidi aumenta da sud a nord con l'aumentare della latitudine.

Negli anni successivi furono condotte numerose altre ricerche che in parte confermarono, anche se non interamente, tali conclusioni, ma in parte dettero resultati contrastanti con esse, soprattutto quelle riguardanti le flore dei paesi tropicali. Tuttavia molte di queste ricerche non si limitarono a studiare questo specifico problema, ma furono estese ad indagare quali fattori ambientali, epiontologici, evolutivi, genetici e di altra natura potevano avere influenza sulla formazione dei poliploidi e sulla sopravvivenza dei diploidi, come pure a tentare di spiegare i processi di formazione degli endemismi, per lo più insulari, con alto livello di ploidia, ed a chiarire molti altri problemi legati a questo argomento. Andò così formandosi una vasta letteratura sintetizzata, nei riguardi delle felci, da Lovis (1977) e Walker(1979). Malgrado le molte ricerche anche più recenti, numerosi problemi rimangono tuttora insoluti.

E' da ritenere molto probabile che l'insorgenza di poliploidi sia dovuta a processi diversi e complessi sotto la spinta di fattori che esercitano la loro azione in maniera differente da zona a zona. Tuttavia quali e quanti e di che natura siano questi fattori è tuttora oscuro, come pure ben poco è noto circa le ragioni per cui in flore ritenute fitogeograficamente affini il rapporto diplodi:poliploidi presenta valori nettamente contrastanti. Malgrado ciò da queste ricerche emerge consistente l'ipotesi che esiste una correlazione tra antichità di una determinata flora ed il numero dei diploidi rispetto ai poliploidi che di essa fanno parte. Questa ipotesi, già adombrata da Stebbins(1942) fu esplicitamente formulata da Reese che, in base ad una ricerca sulla flora desertica del Sahara settentrionale (Reese 1957) e di studi precedenti giunse alla conclusione (Reese 1958: p. 353) che «Je jünger die Flora, um so höher der Anteil der Polyploiden». Penso tuttavia che una tale formulazione sia troppo rigida e non corrisponda bene alla realtà; forse potremmo più semplicemente dire che in una flora, un'alta percentuale di diploidi rispetto ai poliploidi è indice di antichità.

Nuove prove a sostegno di questa ipotesi, che oggi per la sua attendibilità potremmo meglio chiamare teoria, ci vengono fornite da ricerche eseguite anche in tempi più recenti. Mi riferisco in particolare a quelle sulla flora delle Isole Canarie. Le ricerche citologiche di Larsen $(1960,1963)$ sulla loro flora hanno messo in evidenza che i diploidi raggiungono il $77 \%$ ed i poliploidi il $23 \%$ negli endemismi appartenenti alle Angiosperme, e rispettivamente il 75\% ed il 25\% nelle Dicotiledoni. Valori leggermente diversi da questi sono quelli ottenuti da Borgen (1969) relativamente alle piante vascolari (73.5\% diploidi; $26.5 \%$ poliploidi), mentre pressoché uguali sono quelli rilevati da Branwell (1976) sull'intera flora delle Canarie (75.5\% diploidi ; $24.5 \%$ poliploidi). Infine Page (1973) riferisce che più del $70 \%$ delle felci delle Canarie è diploide. E' interessante sottolineare, come già osservato da altri autori, che 
in nessuna flora del mondo è stata riscontrata fino adesso una percentuale di poliploidi così bassa (e di conseguenza una percentuale di diploidi così alta) come nella flora delle Isole Canarie. Pertanto in base alla teoria di Reese dobbiamo concludere, come riconosciuto anche dai suddetti autori, che la flora delle Canarie, essendo caratterizzata da una percentuale molto bassa di poliploidi e molto alta di diploidi, risale a tempi assai remoti . Questa conclusione è in perfetto accordo con i resultati delle indagini condotte in altri campi della botanica, anche se, come sarà chiarito più tardi nel corso della mia esposizione, è da ritenere che la flora delle Canarie ebbe le sue più antiche origini, nell'Eocene-Oligocene, nelle terre che attualmente rappresentano la parte occidentale della Penisola Iberica e dell'Africa mediterranea.

D'altro lato anche Manton (1969) senza nominare questa teoria, ammette l'esistenza di una correlazione tra il rapporto diploidi:poliploidi e l'antichità della flora. Infatti nella difficoltà di spiegare altrimenti la discordanza nella percentuale dei poliploidi da lei riscontrata nelle flore pteridologiche di alcuni paesi tropicali (circa il $60 \%$ in Ceylon, Jamaica ed Africa tropicale occidentale contro il $40 \%$ ed ancor meno in Malaya ed India), Manton ammette che in Malaya ed India, come nel bacino mediterraneo, la flora ricca di diploidi «may represent an ancient Tertiary flora» (p. 220).

Tornando a parlare della flora della Regione Mediterranea, dopo questa lunga digressione intesa a rafforzare l'attendibilità della teoria di Reese, va messo in evidenza che gli unici dati a me noti relativi al rapporto diplodi:poliploidi della flora mediterranea sono quelli di Larsen (1960) basati su una serie di 57 specie di Angiosperme, il $67 \%$ delle quali sono diploidi ed il 33\% poliploidi.

Passando a commentare la Tabella I dobbiamo innanzi tutto osservare che il numero cromosomico di ll entità (appartenenti ai generi Selaginella, Isöetes, Marsilea e Pilularia), delle 124 tra specie e sottospecie che costituiscono la pteridoflora mediterranea, è ignoto.

A questo aggiungasi che in base a quanto risulta dalle ricerche citologiche le 6 specie seguenti presentano più di un numero cromosomico.

Psilotum nudum 2x, 3x, 4x, 8x (cfr. Brownsey e Lovis 1987).

Pteris vittata $4 \mathrm{x}, 6 \mathrm{x}$.

Pteris cretica $2 \mathrm{x}, 3 \mathrm{x}, 4 \mathrm{x}, 6 \mathrm{x}, 8 \mathrm{x}(\mathrm{Ap})$.

Cystopteris fragilis $4 \mathrm{x}, 6 \mathrm{x}, 8 \mathrm{x}$.

Cystopteris dickieana $4 \mathrm{x}, 6 \mathrm{x}$.

Cystopteris viridula 2x, 4x, 6x (cfr. Castroviejo et al. 1986).

Delle suddette 6 specie, mi è stato possibile accertare quale è il citotipo presente nella Regione Mediterranea soltanto di una, Pteris cretica, della quale fino ad oggi è stato segnalato nell'area mediterranea il solo citotipo diploide. Pertanto nella Tabella I ho citato per questa specie soltanto tale citotipo, mentre per le rimanenti 5 specie ho riportato integralmente i valori di tutti i citotipi noti.

Nello stabilire il rapporto diplodi:poliploidi nella pteridoflora della Regione Mediterranea (cfr. Tabella II ) per quanto concerne le 6 specie suddette, Pteris cretica 
è stata considerata come un diploide, mentre Pteris vittata, Cystopteris fragilis e Cystopteris dickieana sono state conteggiate come poliploidi, non essendo noti per esse citotipi diploidi. Al contrario Psilotum nudum e Cystopteris viridula, non potendo essere riferiti né ai diploidi né ai poliploidi, poiché non è finora noto con quale citotipo essi sono presenti nell'area mediterranea, sono stati conteggiati a parte, al pari delle entità di cui non è ancora noto il numero cromosomico.

Con questi accorgimenti è stato stabilito il rapporto diploidi:poliploidi che è indicato in tre sezioni diverse della Tabella II, che riguardano la pteridoflora mediterranea nella sua interezza, gli endemismi ed i relitti.

\begin{tabular}{|c|c|c|c|c|c|c|c|c|c|c|c|c|}
\hline \multirow{3}{*}{ Liwello di ploidia } & \multicolumn{4}{|c|}{ PTERIDOFLORA } & \multicolumn{4}{|c|}{ ENDEMISMI } & \multicolumn{4}{|c|}{ RELITTI } \\
\hline & \multicolumn{2}{|c|}{ A } & \multicolumn{2}{|c|}{$\mathrm{B}$} & \multicolumn{2}{|c|}{ A } & \multicolumn{2}{|c|}{$\mathrm{B}$} & \multicolumn{2}{|c|}{ A } & \multicolumn{2}{|c|}{$\mathrm{B}$} \\
\hline & No. & $\%$ & Ho. & $\%$ & No. & $\%$ & No. & $\%$ & No. & $\$$ & No. & $\$$ \\
\hline Diploidi & 69 & 55.6 & 69 & 55.6 & 10 & 50.0 & 10 & 50.0 & 9 & 69.2 & 9 & 69.2 \\
\hline Triploidi & & 2.4 & & & & & & & 1 & & & \\
\hline Tetraploidi & & 25.8 & & & 2 & 10.0 & & & 2 & 15.4 & & \\
\hline Esaploidi & 4 & 3.2 & 42 & 33.8 & - & - & 2 & 10.0 & - & - & 3 & 23.1 \\
\hline Entità con citotipi tetra- ed esaploidi & 2 & 1.6 & & & - & - & & & - & - & & \\
\hline Entita con citotipi tetra-, esa- ed octoploidi & 1 & 0.8 & & & - & - & & & - & - & & \\
\hline Entità con citotipi diploidi e poliploidi & 2 & 1.6 & 2 & 1.6 & - & - & - & - & 1 & 7.7 & 1 & 7.7 \\
\hline Entità con numero cromosomico ignoto & 11 & 9.0 & 11 & 9.0 & 8 & 40.0 & 8 & 40.0 & - & - & - & - \\
\hline Totali & 124 & 100 & 124 & 100 & 20 & 100 & 20 & 100 & 13 & 100 & 13 & 100 \\
\hline
\end{tabular}

Tabella II.- Livello di ploidia delle specie e sottospecie (A) e rapporto di ploidi: poliploidi (B) nella pteridoflora, negli endemismi e nei relitti della Regione Mediterranea.

I dati riportati nella Tabella II mostrano che nella pteridoflora della Regione Mediterranea il numero dei diploidi è senza ombra di dubbio nettamente superiore a quello dei poliploidi. E' vero che questi dati sono soggetti a mutare poiché oggi, per le ragioni suddette, siamo nell'impossibilità di assegnare alcune entità ai diploidi od ai poliploidi. Tuttavia anche nella eventualità che tutte le entità di incerta assegnazione risultassero poliploidi, la percentuale dei diploidi resterebbe sempre più alta di quella dei poliploidi $(55.6 \%$ contro $44.4 \%)$. Ma a mio avviso è difficile che questa eventualità possa verificarsi. Infatti, in teoria, tenendo presente che le entità di cui non è noto il numero cromosomico sono in gran parte pteridofite primitive ed appartengono a generi in cui le specie diploidi sono più numerose di quelle poliploidi, è presumibile che la percentuale dei diploidi verrà ad aumentare più di quella dei poliploidi.

Questa considerazione vale anche per il rapporto diploidi:poliploidi negli endemismi in quantoché molte delle entità di cui non si conosce il numero cromosomico sono paleoendemismi verosimilmente diploidi. Non escludo che il giorno in cui il numero cromosomico di essi sarà noto, la percentuale dei diploidi raggiunga valori vicini, se non superiori a quello $(69.2 \%)$ dei relitti. In questi ultimi la percentuale dei 
diploidi rispetto ai poliploidi è notevolmente alta. E'improbabile che essa aumenti; infatti l'unica entità d' incerta attribuzione tra i relitti è $P$ silotum nudum ed è presumibile che esso andrà ad aumentare la percentuale dei poliploidi poiché il citotipo più largamente distribuito di questa entità è il tetraploide.

Dall'esame dei dati riportati nella Tabella II, riguardanti il rapporto diploidi:poliploidi, risulta chiaramente che nella pteridoflora mediterranea il numero dei diploidi è nettamente superiore a quello dei poliploidi, sia che venga preso in considerazione il complesso di tutte le entità, sia che si tengano presenti i soli endemismi e relitti. Se, come appare ormai accertato, possiamo ritenere valida la teoria che in una data flora un numero alto di diploidi rispetto ai poliploidi è indizio di una sua antichità, in base a quanto abbiamo osservato sopra dobbiamo concludere che la flora pteridologica della Regione Mediterranea ha origini molto remote nel tempo. Come vedremo, questa conclusione è suffragata da altre fonti di ricerca.

Dobbiano ora esaminare la ripartizione delle specie e sottospecie nelle tre zone della Regione Mediterranea.

\begin{tabular}{|c|c|c|c|c|c|c|c|c|c|c|c|c|c|c|c|}
\hline \multirow{3}{*}{ Settori } & \multicolumn{5}{|c|}{ FTERIDOFLORA } & \multicolumn{5}{|c|}{ ENDEMISMI } & \multicolumn{5}{|c|}{ RELITTI } \\
\hline & \multicolumn{2}{|c|}{$A$} & \multicolumn{3}{|c|}{$\mathrm{B}$} & \multicolumn{2}{|c|}{$A$} & \multicolumn{3}{|c|}{$\mathrm{B}$} & \multicolumn{2}{|c|}{$A$} & \multicolumn{3}{|c|}{$\mathrm{B}$} \\
\hline & No. & $\%$ & $E$ & $\mathrm{~W}$ & 5 & No. & $\%$ & $\mathrm{E}$ & W & S & No. & 9 & $\mathrm{E}$ & $\mathrm{W}$ & $s$ \\
\hline E. & 11 & 8.9 & 11 & - & - & 7 & 35.0 & 7 & - & - & 1 & 7.7 & 1 & - & - \\
\hline$W$ & 23 & 18.5 & - & 23 & - & 6 & 30.0 & - & 6 & - & 6 & 46.1 & - & 6 & - \\
\hline s. & 5 & 4.1 & - & - & 5 & 2 & 10.0 & - & - & 2 & 2 & 15.4 & - & - & 2 \\
\hline$E+W+S$. & 48 & 38.7 & 48 & 48 & 48 & 1 & 5.0 & 1 & 1 & 1 & 1 & 7.7 & 1 & 1 & 1 \\
\hline $\mathrm{E} .+\mathrm{W}$ & 21 & 16.9 & 21 & 21 & - & - & - & - & - & - & 1 & 7.7 & 1 & 1 & - \\
\hline E. + S. & 1 & 0.8 & 1 & - & 1 & - & - & - & - & - & - & - & - & - & - \\
\hline$W .+S$ & 15 & 12.1 & - & 15 & 15 & 4 & 20.0 & - & 4 & 4 & 2 & 15.4 & - & 2 & 2 \\
\hline Totali & 124 & 100 & 81 & 107 & 69 & 20 & 100 & 8 & 11 & 7 & 13 & 100 & 3 & 10 & 5 \\
\hline
\end{tabular}

Tabella III.- Numero delle specie e sottospecie della pteridoflora, degli endemismi e dei relitti presenti nei tre settori (A) ed in ogni singolo settore (B) della Regione Mediterranea.

Dai dati riportati nella Tabella III, che riguarda il complesso dell'intera pteridoflora, risulta che circa due terzi delle specie e sottospecie sono presenti in più di un settore e più di un terzo di esse in tutti e tre i settori. Delle specie presenti in un solo settore (39) quasi due terzi (24) sono rappresentate da endemismi e relitti. Notiamo altresì che la più alta concentrazione la riscontriamo nel settore occidentale e quella più bassa in quello meridionale. Questi dati bene si accordano con le condizioni ambientali delle tre zone, delle quali quella occidentale presenta caratteristiche bioclimatiche più favorevoli per le pteridofite di quella orientale ed ancor più di quella meridionale.

Nei riguardi degli endemismi, contrariamente a quanto sarebbe da aspettarsi, ben 5 entità sono rappresentate in più di un settore della Regione Mediterranea, ma 
dobbiamo tener presente che si tratta di idrofite, legate quindi a particolari condizioni edafiche. Quanto al numero degli endemismi presenti nei tre settori, anche in questo caso il numero più alto si registra nel settore occidentale, ma in proporzione nettamente inferiore rispetto a quella degli altri settori di quanto avviene nel complesso dell'intera pteridoflora. Questo dipende dal fatto che tra gli endemismi esclusivi di un determinato settore, sono più numerosi quelli del settore orientale che quelli dell'occidentale. Ciò non si verifica altrove nei dati forniti nella tabella precedente $\mathrm{e}$ seguente. Questo è forse da imputare al fatto che il numero degli endemismi è più legato a fattori epiontologici che a fattori ambientali.

Nella Tabella III sono riportati anche i valori relativi ai relitti. Come era da prevedere date le caratteristiche ambientali più favorevoli per una flora antica originariamente subtropicale, i relitti sono accantonati in massima parte(46.1\%) nel settore occidentale e come vedremo nelle Sierre di Algeciras. Va notato inoltre che, forse per ragioni epiontologiche, abbiamo valori più alti nel settore meridionale che in quello orientale.

Proseguendo nell'esame della Tabella I, troviamo la colonna indicata con la sigla RM nella quale, per un più diretto confronto con i dati delle colonne seguenti,è segnalata con una croce (+) la presenza di ogni specie e sottospecie della Regione Mediterranea, ad eccezione degli endemismi e relitti, la cui presenza è invece contrassegnata rispettivamente da una $e$ ed una $r$.

Come già anticipato sopra, su 124 specie e sottospecie della pteridoflora mediterranea si annoverano soltanto 20 endemismi. Questo numero non è molto alto e corrisponde soltanto a poco più del $16 \%$, ma si tratta, come già messo in risalto prima, di entità riscontrate fino ad oggi nell'ambito della sola Regione Mediterranea. Questo numero sarebbe più alto se a queste entità fossero aggiunte, come è fatto da alcuni autori, quelle specie e sottospecie con areale ristretto che comprende anche località poste in regioni limitrofe, come per esempio Selaginella balansae o Cosentinia vellea subsp. bivalens.

Alcune caratteristiche degli endemismi sono già state messe in risalto sopra, trattando della citologia. Molto resterebbe ancora da dire, ma non conosco alcuna classificazione degli endemismi cui riferirmi. D'altro lato anche l'inquadramento biogeografico e citotassonomico degli endemismi di Favarger e Contandriopoulos (1961) in 4 tipi (paleoendemismi, patroendemismi, schizoendemismi e apoendemismi), adottato da alcuni studiosi, non è soddisfacente né sul piano teorico né su quello pratico.Sta di fatto che se volessimo accertare l'origine e l'età dei 20 endemismi della pteridoflora mediterranea, dovremmo possedere per molti di essi una conoscenza assai migliore di quella di cui oggi disponiamo.

Quanto ai relitti, come già accennato, la maggior parte di essi sono di età remota, e ritengo che alcuni, per esempio Culcita macrocarpa, Woodwardia radicans e Davallia canariensis, siano vissuti, e forse a lungo, in Europa ancor prima che nella Macaronesia dove oggi hanno una più ampia diffusione.

Nella Tabella I, alla colonna relativa alla pteridoflora mediterranea, sono affiancate 13 colonne nelle quali viene riportata la distribuzione di ogni singola specie 
nei territori limitrofi alla Regione Mediterranea ed in altre parti del mondo. I dati dedotti dall'esame delle 14 colonne della tabella sono riassunti nella Tabella IV.

Ritengo che queste cifre non richiedano particolari commenti; esse esprimono chiaramente la maggiore o minore affinità tra la Regione Mediterranea e le altre regioni del mondo. In base ad esse risulta che la pteridoflora mediterranea è più affine a quella dei territori limitrofi, in particolare con la zona submediterranea, centroeuropea e pontico-sudsibirica e con l'Europa atlantica, che a quella di altre regioni. Ciò era prevedibile; però fa eccezione la flora delle zone aride nord-africane ed asiatiche della quale solo 21 entità sono rappresentate nella Regione Mediterranea, numero questo inferiore a quelli dell'Asia e Malesia (45), del Nordamerica (24) e dell'Africa tropicale (21). Questo a mio avviso non è imputabile ad un grado minore di affinità, ma alle caratteristiche ecologiche delle pteridofite che sono in generale scarsamente rappresentate nelle zone aride. Va notato inoltre, indipendentemente dalla affinità con le zone limitrofe, che la pteridoflora mediterranea ha un numero più alto di specie comuni con la pteridoflora asiatica che con quella dell'Africa tropicale malgrado che questa sia geograficamente più vicina. Verosimilmente ciò è imputabile al fatto che la Regione Mediterranea è bioclimaticamente più affine ai territori asiatici che a quelli dell'Africa tropicale. Questa è forse la stessa ragione per cui la pteridoflora mediterranea ha in comune con l'Africa australe un numero di specie di poco inferiore a quello dell'Africa tropicale, malgrado una distanza notevolmente maggiore della prima rispetto alla seconda dal Mediterraneo.

- Regione Mediterranea

- Endemiche nella Regione

Presenti anche in:

- Europa atlantica (EuA)*

- Zona submediterranea, centroeuropea e pontico-sudsibirica $(\mathrm{Eu})^{*}$

- Asia occidentale: Anatolia, Caucasia ed Iran settentrionale (WAs)* $\quad 54$

- Zone aride nordafricane ed asiatiche (ZA)* $\quad 21$

- Macaronesia (Mac)*

- Africa tropicale (AfT)

- Africa australe (AfA)

- Asia (eccetto Asia occidentale e mediterranea) e Malesia (AsM)

- Australia (Au)

- Nuova Zelanda (NZ)

- Nordamerica (NAm)

- Centroamerica (CAm)

- Sudamerica (SAm)

Tabella IV. Numero delle specie e sottospecie facenti parte della pteridoflora della Regione Mediterranea, ivi endemiche, o presenti anche altrove nei territori limitrofi (*) e nelle rimanenti parti del mondo.

Per concludere la nostra ricerca, dopo aver trattato dell'affinità, dobbiamo rivolgere la nostra attenzione all'origine della flora pteridologica della Regione Mediterranea. Indagando sul rapporto diploidi:poliploidi sono giunto alla conclusione, del resto convalidata da altre fonti di ricerca, che la pteridoflora mediterranea è assai antica. Resta ora di riandare indietro nel tempo per rintracciare a quando possiamo far 
risalire le sue origini. Purtroppo ben scarso è l'aiuto che ci viene fornito dai fossili e pertanto siamo costretti a basare la nostra ricerca sullo studio corologico ed epiontologico delle specie più significative che fanno parte della flora pteridologica mediterranea attuale, delle specie affini e dei loro presunti progenitori.

$$
* * *
$$

L'origine, evoluzione e diffusione della flora mediterranea dipendono in larga misura dalle vicende geologiche, paleogeografiche e paleoclimatiche cui le terre oggi corrispondenti all'area mediterranea andarono incontro nel passato. Appare pertanto opportuno, avanti di passare a trattare dell'origine della pteridoflora mediterranea, tracciare un quadro, necessariamente il più conciso possibile, di queste vicende, prevalentemente centrato su quegli avvenimenti che maggiormente ebbero influenza sulla genesi del popolamento vegetale.

Come è noto, e come è ormai unanimamente riconosciuto, il nostro pianeta era costituito nel tardo Paleozoico da un'unica massa terrestre (Pangea) emergente da una vasta distesa di acque (Pantalassa). Si ritiene che nel Permiano la Pangea fosse costituita da due grandi masse continentali, una settentrionale, Laurasia, ed una meridionale, Gondwana, saldate assieme ad occidente, ma separate ad oriente da un ampio oceano denominato Tetide o Paleotetide. Successivamente, alla fine del Triassico-inizio del Giurassico andò formandosi ad ovest l'Oceano Atlantico centrale che portò alla separazione parziale della Laurasia dalla Gondwana. A partire dal Cretaceo inferiore ebbe inizio l'apertura dell'Oceano Atlantico meridionale che determinò una fratturazione della Gondwana in due masse distinte: il Continente Africano e l'America meridionale. Contemporaneamente iniziò anche l'apertura dell'Oceano Indiano con la frammentazione dell'Antartide e dell'Australia e l'individuazione di un terzo frammento, assai più piccolo, formato da quel lembo di terra che andò molto più tardi nel Cenozoico a formare con deriva verso nord l'India peninsulare entrando in collisione con l'Asia e contribuendo al sollevamento del Tibet e successivamente della Catena Himalayana. Al principio del Cretaceo superiore, mentre i fenomeni di deriva proseguivano e tra questi l'allontanamento dell'America meridionale dall'Africa, andava delineandosi il distacco dell'America settentrionale dall'Europa ed iniziò la compressione tra Eurasia ed Africa.

Alla fine del Mesozoico (65 M.A.) l'America meridionale si era notevolmente allontanata dall'Africa, consentendo all'Oceano Atlantico di raggiungere una larghezza di poco inferiore alla metà di quella attuale; anche la zolla dell'India peninsulare si era maggiormente ravvicinata all'Asia, ed a nord la zolla africana iniziava a venire a contatto con l'Eurasia. Antartide ed Australia formavano ancora una massa unica.

I movimenti di deriva e di rotazione dei continenti proseguirono anche durante il Cenozoico. L'America meridionale andò allontanandosi sempre più dall'Africa e si portò maggiormente a nord finendo per ricongiungersi al Nordamerica grazie al sollevamento di nuove terre nella zona interposta tra esse. La frattura tra l'Europa e l'America settentrionale andò ampliandosi fino a raggiungere il bacino artico, causando così il distacco della Groenlandia dall'Eurasia. Anche Australia ed Antartide iniziarono il loro allontanamento. 
All'inizio del Paleocene l'estremità occidentale dei bracci di oceano della Neotetide e la Mesogea costituirono un ampio spazio di mare, aperto verso l'Atlantico, limitato a nord dalla placca Iberica e da quella Europea, ed a sud dalla vasta placca Africana.

Nell'Eocene il movimento compressivo tra i due cratoni, europeo ed africano, portò alla collisione tra la placca iberica e la placca europea e dette luogo alla formazione dei Pirenei. Vasti fenomeni di obduzione e subduzione, con polarità opposte, portarono a profonde trasformazioni che si concretarono nella formazione della Catena Dinarico-Ellenica e della Catena Alpina. Questi eventi furono anche il preludio di quelli che si conclusero più tardi, nel Miocene.

L'Oligocene superiore (25-24 M.A.) segna l'inizio della tectogenesi dell'arco Maghrebide-Appenninico che condusse più tardi alla formazione dei rilievi montuosi nordafricani, dell'Appennino e della Cordigliera Betica.

Nel corso del Miocene si verificarono eventi di notevole importanza. Nell'Aquitaniano (23 M.A.) ebbe inizio il distacco della microplacca corso-sardobalearica dalla placca europea. Le Baleari si allontanarono dalla costa valenziana, mentre più a nord Corsica e Sardegna, già d'allora separate tra loro, insieme al basamento paleo-calabro, si staccarono dalla costa francese ed intrapresero la loro traslazione verso oriente con movimento antiorario. Il distacco di questi microcontinenti portò alla formazione di bacini originatisi dietro la loro scia. Inoltre nell'AquitanianoBurdigaliano si verificò la chiusura ad oriente della Mesogea, mentre nel Burdigaliano medio fu conclusa la separazione delle Baleari dal continente europeo. Nel Langhiano (17-16 M.A.) la traslazione e la rotazione della Corsica e Sardegna, sempre separate tra loro, è compiuta, ma l'estremo nord della Corsica era ancora in connessione con l'area ligure dell'arco appenninico, connessione che terminò nel Tortoniano. Il basamento paleo-calabro continuò invece la sua migrazione fino a raggiungere, dopo oltre $900 \mathrm{~km}$. di traslazione, la sua posizione attuale nell'Appennino meridionale in tempi post-miocenici. In questo periodo e nella prima parte del seguente (Serravalliano, 15-13 M.A.), il Mediterraneo comunicava con l'Oceano Atlantico attraverso una soglia, nella Andalusia, interposta tra la Cordigliera Betica e la Meseta Iberica, ed un'altra soglia, nel Marocco, tra il Rif e la Meseta Marocchina apertasi nel Serravalliano superiore, in una fase di grande espansione marina. Il periodo seguente, il Tortoniano (10-9 M.A.) fu caratterizzato da un'intensa fase tettonica generalizzata, sviluppatasi anche lungo tutto l'arco appenninico. Probabilmente fu nell'ultima parte di questa attività che ebbe inizio il sollevamento delle terre corrispondenti alle due suddette soglie.

Il Messiniano (9-5.3 M.A.) fu il periodo più singolare e biologicamente più importante del Miocene. Per effetto dei movimenti crustali che si verificarono all'estremità occidentale dell'area mediterranea, si concretizzò in questo periodo il sollevamento della Cordigliera Betica ed al tempo stesso delle catene nord-africane, Rif e Meseta Marocchina, connesse con essa ad arco, nella zona di Gibilterra. Le due soglie che mettevano in comunicazione il Mediterraneo e l'Oceano Atlantico vennero così a ridursi notevolmente. Di conseguenza nel volgere di poche migliaia di anni il 
Mediterraneo andò incontro ad una ragguardevole regressione e fu soggetto ad una sempre più intensa evaporazione che fu causa di un sensibile aumento della salinità del mare dando luogo alla deposizione di una considerevole quantità di evaporiti. Il Mediterraneo fu così trasformato in una serie di bacini, separati tra loro, occupati da lagune con una elevata salinità, mentre nelle zone circostanti il mare si instaurarono condizioni ambientali caratterizzate da un'accentuata aridità; due fenomeni che incisero in maniera determinante sul popolamento vegetale ed animale dell'area mediterranea. Si ritiene che essi non ebbero carattere di continuità, e fasi di disseccamento si alternarono a fasi di trasgressione marina e si ebbe anche, sul finire del Messiniano, afflusso di acqua dolce nella zona nord-orientale, dando luogo alla formazione di laghi.

Importanti eventi si verificarono nella Regione Mediterranea anche durante il Pliocene (5 .3-1 .6 M.A.). Probabilmente in seguito a moti di scorrimento orizzontale tra i due grandi blocchi continentali, l'europeo e l'africano, l'arco di Gibilterra, forse già inciso nell'ultima parte del Messiniano, venne a riaprirsi. Fu così ristabilita la comunicazione tra Oceano Atlantico e Mediterraneo, ed in tempo assai breve alla catastrofica regressione del Messiniano tenne dietro una grande trasgressione marina che fu uno degli eventi che maggiormente caratterizzarono il Pliocene. Il mare sommerse vasti territori non soltanto nelle zone costiere ma anche nell'interno, spingendosi lungo le valli fino ai piedi di rilievi montuosi, formando numerose penisole ed isole, talune di vasta dimensione. Anche gran parte della pianura padana e veneta venne sommersa. Nel versante tirrenico dell'Appennino settentrionale una fase distensiva condusse la catena ad assumere la sua forma definitiva. L'ampliamento, a partire da nord, dello spazio tirrenico, per distensione e lacerazione crostale, si concluse con l'apertura del Tirreno. Durante il Pliocene possiamo quindi ritenere che la catena appenninica avesse raggiunto la sua posizione attuale. In questo periodo si ebbe inoltre un'intensa attività vulcanica che, specialmente in Italia, ebbe notevoli ' conseguenze e portò alla formazione di vari rilievi montuosi ed isole.

Il Pleistocene fu anch'esso un periodo biologicamente molto importante. Infatti in un tempo relativamente breve si verificarono quattro glaciazioni, di varia intensità, durante le quali i paesi settentrionali ed i monti più alti furono coperti di ghiacci. In corrispondenza di esse si ebbero anche regressioni marine durante le quali l'abbassamento del livello del mare permise connessioni terrestri prima impossibili. Tra una glaciazione e l'altra si ebbero periodi interglaciali di varia lunghezza, in corrispondenza dei quali il livello del mare venne a ristabilirsi od a causare lievi trasgressioni.

Sebbene la Regione Mediterranea fosse in massima parte esente da una diretta influenza dei ghiacci, la sua flora, per effetto delle glaciazioni, andò incontro ad un notevole impoverimento e ad una considerevole riduzione della sua area. Altri eventi del Pleistocene riguardano il vulcanismo che non si limitò alla continuazione della attività pliocenica, ma portò anche alla formazione ed emersione di nuove isole.

A queste notizie sulla Geologia e Paleogeografia ho ritenuto opportuno affiancare un quadro, sia pure necessariamente sommario sulla paleoclimatologia. 
Purtroppo ben poco è noto nei riguardi dell'area mediterranea e quanto è stato scritto in proposito è basato principalmente su studi palinologici di altre regioni, talora anche molto lontane, ed inoltre intesi ad illustrare le vicende della vegetazione legnosa trascurando del tutto le pteridofite, od al massimo limitandosi a ricordare la maggiore o minore frequenza di esse. Gli unici lavori in cui sono reperibili maggiori ragguagli riguardano il Messiniano (Trevisan 1967; Bandy 1973; Benda 1973; Bertolani e Cita 1975; Bocquet et al. 1978; Mariotti Lippi 1989; Cita e Corselli 1990) ed in assai maggior misura il Quaternario e soprattutto il Postglaciale.

Nel mio lavoro sulla pteridoflora della Regione Mediterranea (Pichi Sermolli 1979) parlando delle varie vicende geologiche dell'area mediterranea accennai brevemente anche alle sue caratteristiche paleoclimatiche. Qualche anno più tardi Jermy (1984) riprese questo argomento aggiornandolo in base ai lavori comparsi nel frattempo . Mi limito pertanto a riassumere quanto fu scritto nei due suddetti lavori, con l'aggiunta di ulteriori notizie e precisazioni.

Dovremmo innanzi tutto accennare alle condizioni climatiche del tardo Paleozoico, presumibilmente non molto dissimili da quelle dei paesi equatoriali attuali, ma forse in quel tempo nell'area mediterranea erano presenti soltanto i lontani progenitori delle più primitive tra le Pteridophyta attuali. Occorre giungere fino al Giurassico per trovare in Europa una flora pteridologica che abbia strette affinità con le pteridofite di oggi. Di essa facevano parte (Harris 1961) rappresentanti di tre soli generi tuttora viventi: Equisetum, Marattia e Dicksonia. Questa flora ci testimonia un clima di tipo tropicale. Forse non molto dissimili furono le condizioni climatiche del Cretaceo, sebbene si abbiano indizi che nell'America settentrionale si verificarono mutamenti climatici, quali inverni più freddi, dei quali ci sono testimoni fasi con vegetazione di latifoglie decidue (Berry 1930) e, nel Maestrichtiano, flore polliniche e filliti cui corrispondono cambiamenti faunistici (Van Valen e Sloan 1972).

Comunque nell'area mediterranea condizioni di clima tropicale perdurarono a lungo, almeno fino all'Eocene medio (45 M. A.) quando, in base ai calcoli di Wolfe (1978), la foresta tropicale umida e l'isoterma di $25^{\circ} \mathrm{C}$ si trovavano spostati verso nord di almeno $20^{\circ} \mathrm{o}$ addirittura $30^{\circ}$ rispetto al loro limite settentrionale attuale.

$\mathrm{Si}$ ritiene che alla fine dell'Eocene si verificò un graduale raffreddamento e probabilmente nell'Oligocene, nei settori occidentale ed orientale della Mesogea andò affermandosi un clima caldo umido di tipo subtropicale, cui forse facevano riscontro condizioni climatiche tendenzialmente subcontinentali nelle zone interne. Senza dubbio anche la flora e la vegetazione andarono evolvendosi in relazione ai mutamenti climatici e presumibilmente nel settore occidentale s'instaurarono cenosi di laurisilve non molto dissimili da quella che ancor oggi, sebbene notevolmente ridotta in estensione e profondamente danneggiata dall'uomo, è presente nelle Canarie e della quale sono noti reperti fossili pliocenici (Schmincke 1968).

I grandi eventi geologici che caratterizzarono il Miocene furono accompagnati da notevoli cambiamenti climatici. A partire dal Tortoniano inferiore e forse ancor prima, il clima caldo umido andò rapidamente evolvendosi verso una marcata continentalità che caratterizzò, anche se non costantemente, tutti i periodi seguenti 
fino alla fine del Messiniano. La ricca flora tropicale e subtropicale dell'EoceneOligocene andò in gran parte estinguendosi, incapace di spostarsi verso sud a causa del progressivo disseccamento del Sahara. Così le laurisilve lasciarono il posto a steppe, praterie ed altre cenosi semi-aride, alternate a foreste mesofile lungo le rive dei laghi e fiumi e nelle vallate pedemontane. Tuttavia le laurisilve mediterranee riuscirono a sopravvivere nella parte occidentale della Penisola Iberica ed in quella settentrionale del Marocco. Forse già nel Langhiano-Serravalliano, secondo Gvirtzman e Buckbinder (1977), si ebbero periodi di particolare aridità, ma il disseccamento più accentuato, accompagnato da un sensibile aumento della salinità, si ebbe nel Messiniano, quando si verificò un notevole abbassamento del Mediterraneo. Si ebbe allora un profondo rimaneggiamento della flora reso possibile dal basso livello del mare, che aprì nuove vie di immigrazione ad entità orientali e settentrionali, essendosi stabilite varie connessioni tra le terre continentali e le isole del Mediterraneo. E' probabile tuttavia che questo rimaneggiamento si fece sentire in misura assai attenuata nella fascia occidentale iberica e nord africana prospiciente l'Atlantico che ebbe modo di fruire di un clima oceanico e sufficientemente caldo da consentire la sopravvivenza di almeno una parte della flora oligocenica di cui ancor oggi noi abbiamo testimonianza attraverso alcuni relitti ivi accantonati in zone di rifugio di inestimabile valore naturalistico.

Il Pliocene, con la sua grande trasgressione marina, segnò la fine dell'aridità e l'inizio della regressione degli elementi xerofili, mentre i superstiti dell'antica flora terziaria ebbero modo di espandersi di nuovo dalla fascia costiera dove avevano trovato rifugio verso le zone più interne. Tuttavia, il successivo deterioramento del clima favorì anche l'immigrazione di elementi settentrionali.

Le glaciazioni pleistoceniche inferirono un altro duro colpo alla flora mediterranea. Il grande raffreddamento dei paesi boreali e l'incalzare dei ghiacci costrinse la flora nordica a migrare verso sud e le piante montane verso la pianura. Numerose specie invasero la nostra regione e la flora mediterranea dovette ritirarsi di fronte ad esse, spostandosi gradualmente verso territori sempre più meridionali dove in parte sopravvisse in stazioni relitte, ma in parte andò estinguendosi. Tuttavia, durante gli interglaciali la flora mediterranea cercó di espandersi verso nord, ma il successo fu solo temporaneo.

Soltanto nel Postglaciale, con il miglioramento del clima, la flora mediterranea si spinse di nuovo verso nord seguendo il ritiro delle piante nordiche ed alpine. Così, sebbene notevolmente impoverita, essa tentò di rioccupare i vecchi territori, ma vi riuscì soltanto in scarsa misura ed oggi popola solamenteuna esigua fascia costiera lungo il Mediterraneo.

$* * *$

Tornando a parlare dell'origine della flora pteridologica, dopo questa lunga digressione, desidero ricordare che nel mio lavoro sulla pteridoflora mediterranea (Pichi Sermolli 1979) suddivisi le entità ad essa appartenenti, in totale 98, in due gruppi principali: quelle probabilmente presenti nella Regione Mediterranea sin dal 
Terziario, e quelle presumibilmente ivi immigrate nel Quaternario; le prime più numerose delle seconde. Basandomi prevalentemente sulla distribuzione geografica, divisi questi due gruppi principali in vari sottogruppi cercando di stabilire la loro origine. Senza rinnegare i principi cui allora mi ispirai, ma al tempo stesso riconoscendo che quanto scrissi allora va in parte riveduto dato l'enorme quantità di dati nuovi che si sono accumulati in questi ultimi dieci anni, non soltanto in campo botanico, ma anche in quello geologico e paleontologico, ritengo oggi che per lo studio dell'origine ed evoluzione della pteridoflora mediterranea sia più proficua un'analisi delle specie più significative dal punto di vista epiontologico, con areale non molto esteso, piuttosto che una analisi di tutte le entità delle flora ivi comprese quelle con ampia distribuzione, tanto più che di queste fu parlato estesamente nel mio lavoro sulla pteridoflora mediterranea (Pichi Sermolli 1979) e non molto avrei da aggiungere. Pertanto mi limito qui a prendere in esame alcune specie che ci consentono di individuare i territori nei quali andarono formandosi ed evolvendosi i progenitori della attuale flora pteridologica e le vie seguite nella loro migrazione verso il Mediterraneo, cercando di ipotizzare il tempo al quale possiamo far risalire questi eventi. Nella scelta delle specie ho dato la preferenza a quelle diploidi, ritenendo che su esse, più che sui tetraploidi, dobbiamo basarci per stabilire l'origine di una flora.

Un contingente non trascurabile della flora mediterranea provenne indubbiamente dalle regioni orientali. Varie specie ci testimoniano una tale origine. Alcune, le più antiche, discendono presumibilmente da progenitori facenti parte della flora che nel Mesozoico si presume coprisse la parte meridionale del continente asiatico, ancor prima che nell'Eocene (Luteziano) avesse inizio la collisione dell'India peninsulare con l'Eurasia. E' da ritenere che queste specie si diffusero nell'area mediterranea lungo i territori meridionali che delimitavano la Tetide.

Una di queste specie è Woodwardia radicans. Circoscritto in senso stretto, il genere Woodwardia consta di 9 specie distribuite (Fig. 2) in tre aree nettamente disgiunte : una con 6 specie [ $W$. auriculata Blume, $W$. cochin-chinensis Ching, $W$. japonica (L. fil.) Sm., W. orientalis Sw., W. prolifera Hook. et Arnott, e W. unigemmata (Makino) Nakai] in Asia meridionale e Malesia dove ritengo ebbe il suo centro di differenziazione; una (W. radicans) nel Mediterraneo e Macaronesia e due ( $W$. fimbriata Sm. e W. spinulosa M. Martens et Galeotti) nella parte sud-occidentale degli Stati Uniti e Centroamerica . La specie più affine a Woodwardia radicans è W. unigemmata del sud-est asiatico, Himalaya e Filippine, con la quale è da taluni autori ritenuta conspecifica. Woodwardia è un genere molto antico, noto allo stato fossile in America già nel Paleocene e strettamente affine al genere fossile Woodwardites rappresentato nel Giurassico inferiore della Franconia e nell'Oligocene della Sassonia. Questi reperti e la distribuzione geografica inducono a pensare che Woodwardites, o forse addirittura Woodwardia, fosse largamente distribuita nella Laurasia già prima che le terre dell'America settentrionale si staccassero dall'Europa (Cretaceo superiore).

Culcita macrocarpa è un'altra specie che ritengo sia da riferire a questo gruppo. Il genere Culcita è stato recentemente sottoposto a revisione (White e Turner 1988) e suddiviso in due generi, Culcita K. Presl e Calochlaena (Maxon) M. D. Turner et 
R.A. White, bene distinti tassonomicamente e corologicamente (Fig. 3) tra loro. Culcita consta di 2 specie, una (C. macrocarpa) presente nella Penisola Iberica e Macaronesia, l'altra [ $C$. coniifolia (Hook.) Maxon] nei tropici dell'America centrale e meridionale. Calochlaena comprende 5 specie [ $C$. dubia (R. Br.) M.D. Turner et R.A. White, C. straminea (Labill.) M.D.Turner et R. A. White, C. javanica (Blume) M. D. Turner et R. A. White, $C$. villosa (C. Chr.) M. D. Turner et R. A.White e $C$. novae-guineae (Rosenstock) M. D. Turner et R. A. White] distribuite nella Malesia, Melanesia, Figii, Samoa, Australia orientale e Tasmania. Pur essendo d'accordo con White e Turner nel separare Calochlaena da Culcita a livello di genere, ritengo erroneo affermare che essa « is evidently only remotely related to Culcita» (p. 94). Al contrario, d'accordo con Holttum (1963) ed altri autori, penso che i due generi siano affini tra loro tanto da ipotizzare che ebbero un'origine comune. Probabilmente si formarono durante il Giurassico nella fascia meridionale della Laurasia. Partendo da tale ipotesi, appare logico pensare che Culcita, od il suo predecessore, si diffuse verso occidente fino a raggiungere l'Europa e l'America meridionale prima ancora che nel Cretaceo inferiore le due masse continentali iniziassero ad allontanarsi l'una dall'altra. Ritengo comunque che Culcita macrocarpa rappresenti un relitto mesozoico.

Penso che a questo contingente debba essere riferita anche Davallia canariensis distribuita nella Penisola Iberica (Cornice Cantabrica, provincie portoghesi costiere a nord del Tajo ed Andalusia sud-occidentale), Marocco (Penisola Tingitana, Monte Gurugu a sud di Melilla, Uadi Drâa inferiore) e Macaronesia. E'questa una specie fitogeograficamente isolata dal rimanente del genere costituito da una quarantina di specie quasi esclusivamente distribuite nei tropici e subtropici del vecchio mondo ed in prevalenza nell'Asia, Malesia ed isole oceaniche fino alla Polinesia. Il genere è presente anche in Africa tropicale dove è nota una sola specie, Davallia chaerophylloides (Poir.) Steud., distribuita in varie zone tropicali e subtropicali dall'Etiopia alla Guinea e dal Natal all'Angola. Il fatto che Davallia canariensis non mostri alcuna particolare affinità con detta specie malgrado che gli areali delle due specie siano abbastanza vicini tra loro e mostra invece varie caratteristiche in comune con le specie orientali, m'induce a pensare che esse ebbero origine in due regioni differenti ed a ritenere che anche Davallia canariensis appartenga a quel contingente antico che ebbe i suoi lontani progenitori nell'Asia sud-orientale.

Altre specie, presumibilmente di origine cenozoica, in un tempo più recente, si diffusero dall'Asia nella Regione Mediterranea. Esse fanno parte di quel contingente che ebbe il suo centro di evoluzione nell'Asia occidentale, prevalentemente nel Caucaso, Transcaucasia e nella catena dell'Elburz, la cui migrazione verso occidente si effettuò lungo i territori che allora emergevano dalla Neotetide.

Una di esse è Dryopteris filix-mas, originatasi con probabilità nella Caucasia dove tuttora vivono i suoi progenitori diploidi Dryopteris oreades e Dryopteris caucasica (A. Braun) Fras.-Jenk. et Corley, ed i relativi ibridi. La sua ampia distribuzione fa pensare ad un'origine sicuramente antica risalente con probabilità all'Eocene. Un'altra specie è Dryopteris pallida che presumibilmente ebbe il suo centro di evoluzione nell'Asia occidentale con la formazione di una sottospecie 


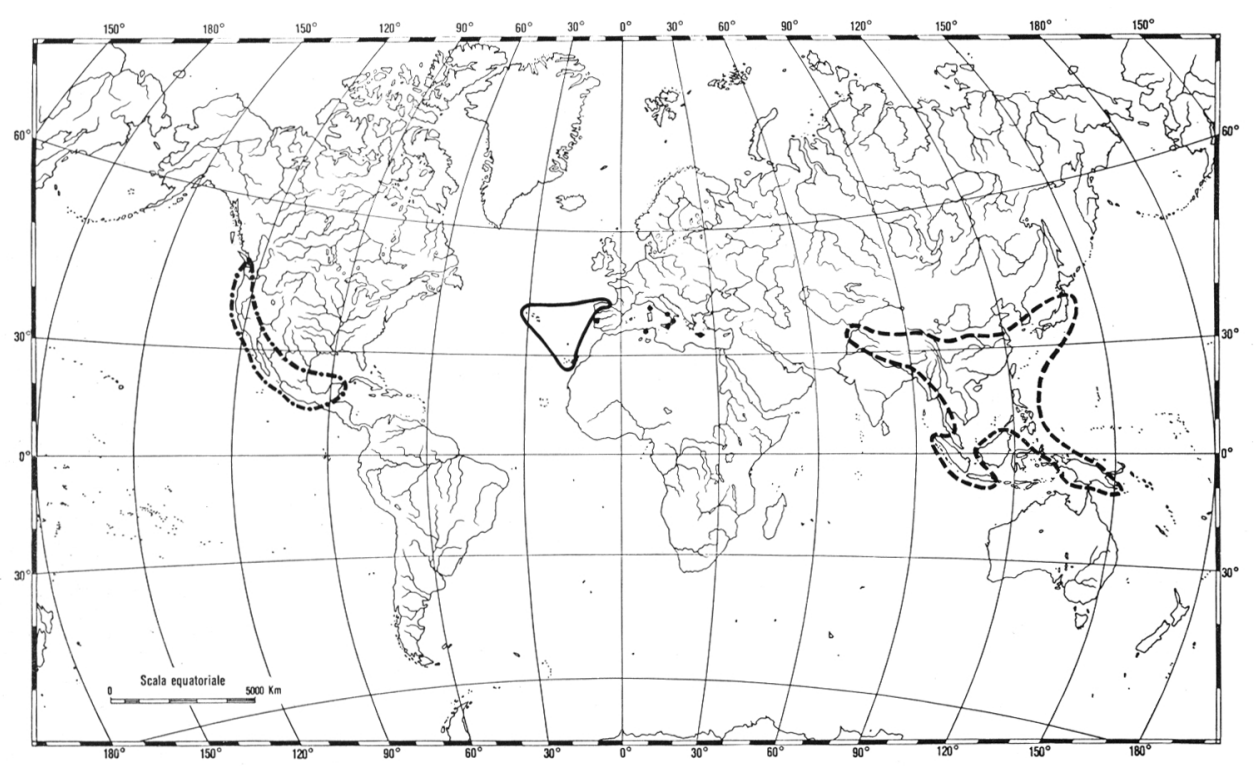

Fig. 2. Areale del genere Woodwardia: W. radicans $-(\bullet) ;$ W. auriculata, W. cochinchinensis, $W$. japonica, $W$. orientalis, $W$. prolifera, $W$. unigemmata $-{ }_{-} ; W$. fimbriata, W. spinulosa -

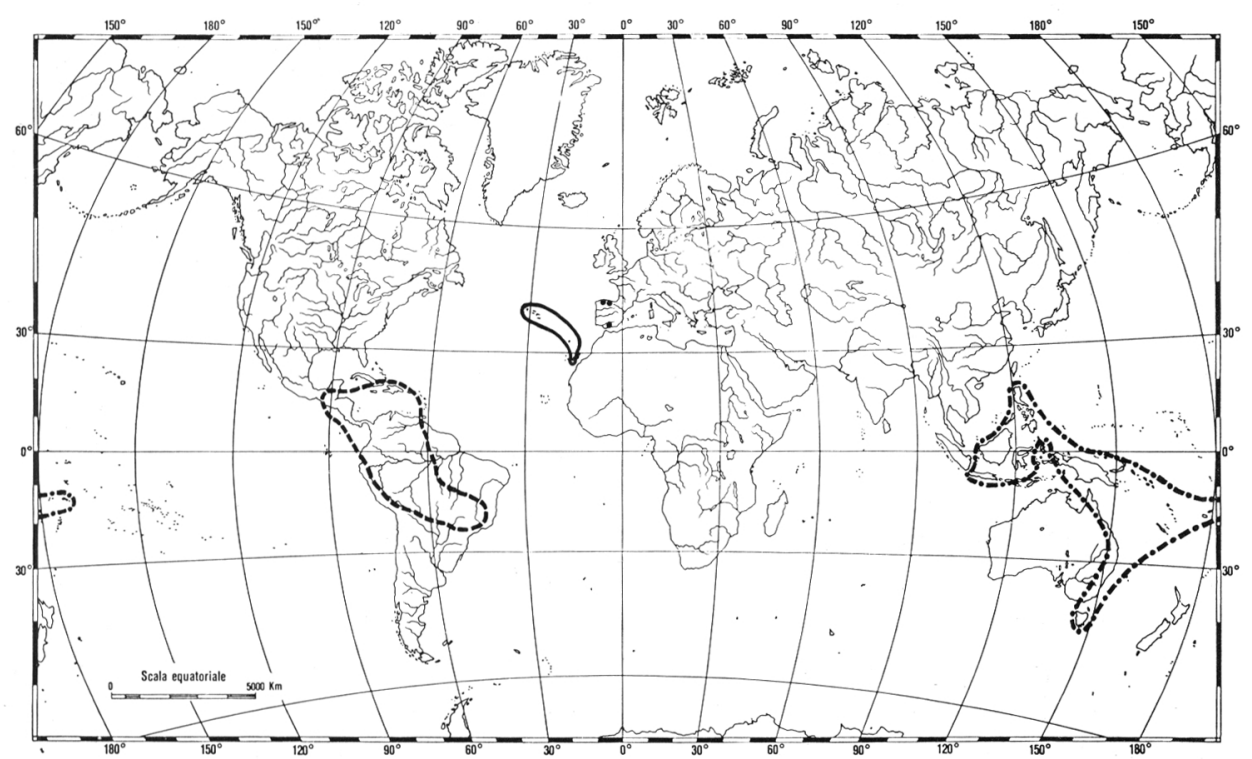

Figura 3. Areale del genere Culcita (C. macrocarpa $(\bullet) ;$ C. coniifolia 
nell'Azerbaijian e Nord Iran lungo il Mar Caspio, [subsp. raddeana (Fomin) Nardi]; ed una nella Siria, Libano ed Israele, [subsp. libanotica]; per poi diffondersi ampiamente verso occidente nella sua forma tipica fino alle Baleari dove si differenziò una terza sottospecie, [subsp. balearica]. Probabilmente anche Asplenium septentrionale, una specie tassonomicamente e geneticamente isolata, si originò nella Caucasia dove si trova tuttora il suo progenitore diploide, subsp. caucasicum Fras.-Jenk. et Lovis.

Dobbiamo ora dedicare la nostra attenzione alle specie di origine africana. Anche se alcune di esse in definitiva sono discendenti di flore molto antiche, tra le specie oggi presenti nella Regione Mediterranea, una sola, Selaginella balansae, ha origini così remote da poter ritenere che risalga a tempi mesozoici, come alcune pteridofite asiatiche di cui ho parlato sopra.

Selaginella balansae è accantonata in una ristretta zona del Marocco a cavallo tra la Regione Mediterranea e la Regione Saharo-Arabica, e pertanto è da considerare come un paleoendemismo, anche se non endemica della sola Regione Mediterranea. Questa specie appartiene al gruppo di Selaginella rupestris (L.) Spring, più precisamente a Selaginella subgen. Selaginella sect. Tetragonostachys (A. Braun ) Hieron., series Arenicolae Tryon, di cui fanno parte altre 5 specie distribuite nella parte meridionale degli Stati Uniti e nel Messico (Fig. 4). Si tratta di un gruppo che possiede le caratteristiche più primitive della sezione Tetragonostachys. Forse Selaginella balansae è la specie più antica della pteridoflora mediterranea ed al pari di varie specie di latitudini australi, quali Grammitis poeppigiana (Mett. ) Pic. Ser., Blechnum pennamarina (Poir. ) Kuhn ed altre (cfr. Pichi Sermolli e Bizzarri 1978), è da considerare che risalga alla Gondwana. Forse è un relitto di una flora xerofila presente nell'Africa settentrionale prima ancora che la massa dell'America settentrionale si staccasse dall'Africa, e la parte settentrionale di quest'ultima, per la lontananza dal mare, era presumibilmente caratterizzata da un'accentuata continentalità climatica, favorevole alla formazione ed evoluzione di una flora xerofila.

Varie sono le specie di origine cenozoica che provengono direttamente od attraverso i loro progenitori dall'Africa tropicale. Molte Pteridofite e Spermatofite ebbero il loro centro di origine nei grandi massicci montuosi dell'Etiopia, Kenya, Tanzania, Uganda, Zaire, Rwanda e Burundi. Da questi massicci i discendenti di esse si diffusero a raggiera verso altre regioni (Fig. 5) raggiungendo: verso sud l'Africa meridionale, dove taluni formarono centri secondari di evoluzione molto attivi, il Madagascar od anche l'Angola; verso est lo Yemen, l'India, l'Himalaya e lo Yunnan; verso ovest, lungo la fascia equatoriale e tropicale, alcuni paesi del Golfo di Guinea, prevalentemente il massiccio del Camerun; ed infine verso nord la Regione Mediterranea e la Macaronesia.

Vari studiosi hanno rivolto la loro attenzione alle vie di migrazione riguardanti l'Africa. Non potendo dilungarmi su questo argomento, tra i tanti lavori pubblicati anche recentemente, in massima parte concernenti le Angiosperme, mi limito a citare quelli di Croizat (1958, 1965, 1968), Wickens (1976), Quézel (1978) e Braumwell (1986), aggiungendo alcune considerazioni personali emerse dalle mie ricerche pteridologiche. 


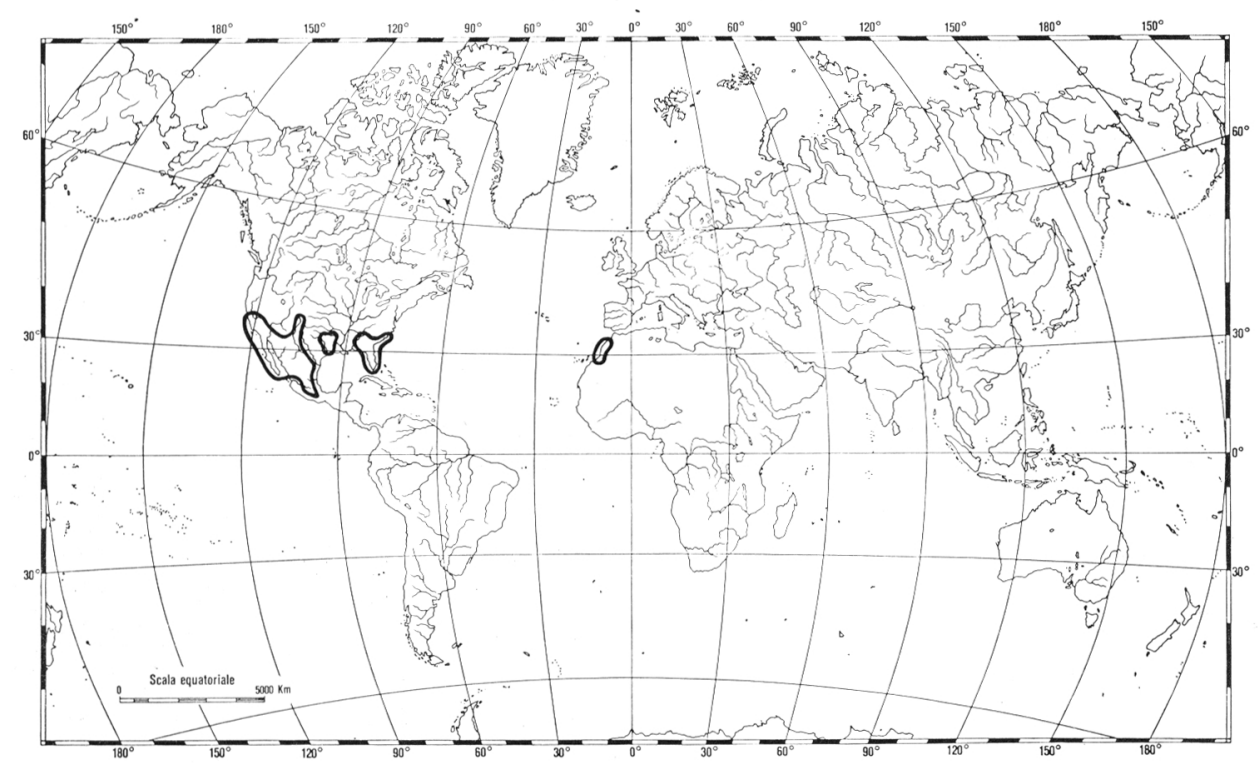

Fig. 4. Areale di Selaginella sect. Tetragonostachyss ser. Arenicolac.

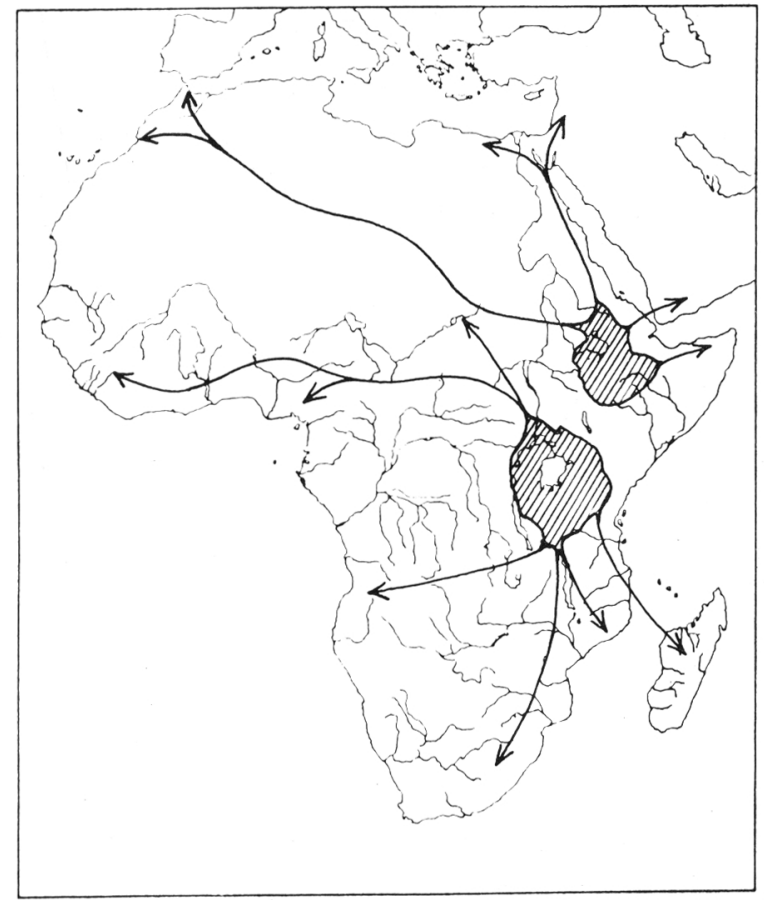

Fig. 5. Vie di migrazione dai massicci montuosi dell'Africa tropicale nord-orientale ed orientale verso l'Europa, Asia ed altre parti dell'Africa. 
In teoria potremmo pensare che la via di migrazione di quest'ultimi passasse per l'Africa tropicale occidentale data la vicinanza con le isole del Capo Verde, ma non vi sono testimonianze, almeno tra le pteridofite, di una tale via di migrazione. Come già ipotizzai anni addietro (Pichi Sermolli 1979), ritengo invece che la migrazione verso nord avvenne seguendo due diverse direttrici: una attraverso il Sahara, l'altra lungo i territori che fiancheggiano il Mar Rosso.

La migrazione attraverso il Sahara si svolse verso nord-ovest e fu notevolmente agevolata dalla presenza dei rilievi montuosi del Jebel Marra, Ennedi, Tibesti, Tassili ed Hoggar che offrirono condizioni ambientali favorevoli per la sopravvivenza di molte piante. L'esistenza di questa via di migrazione ci è testimoniata dalla presenza non solo di relitti viventi nei vari rilievi montuosi sopra ricordati, ma anche da reperti palinologici fossili ivi rinvenuti. Si presume che questa via fu seguita anche da varie specie di Angiosperme delle quali un esempio è Erica arborea L. Di questa, in base ai dati forniti da Bruneau de Miré e Quézel (1959), Quézel (1978) ed Hedberg (1961) sono note stazioni relitte e reperti che ci testimoniano chiaramente come questa specie dai massicci montuosi dell'Africa tropicale orientale raggiunse la Regione Mediterranea attraverso il Sahara. Indubbiamente, anche se mancano testimonianze così probanti, altre Angiosperme migrarono lungo questa direttrice verso nord-ovest; tra queste anche il genere Canarina che dai suddetti massicci dove verosimilmente ebbe origine e dove è rappresentato da due specie (Hedberg 1961) si diffuse con una specie fino alle Canarie. Ritengo che questa fu la via seguita, prima del disseccamento del Sahara che si ritiene ebbe inizio nel Miocene medio, dalle pteridofite igrofile tropicali e subtropicali che entrarono a far parte della flora mediterranea. Alcuni studiosi sostengono che anche in tempi più recenti specie di spermatofite raggiunsero il Mediterraneo lungo questa via, ma lo ritengo improbabile e forse si trattò di piante xerofile, non certo delle pteridofite di cui dobbiamo iniziare a parlare.

Tra le varie specie di origine africana che a mio avviso raggiunsero la Regione Mediterranea attraverso questa via di migrazione, ricordo prima di tutte Pteris incompleta il cui areale è limitato alla Spagna meridionale (Sierre di Algeciras ), Marocco (Penisola Tingitana) e Macaronesia (excl. Isole del Capo Verde). Tassonomicamente è specie bene distinta, tanto che la sua affinità non è del tutto chiara. A mio avviso, la specie più vicina ad essa tra le africane è Pteris dentata di cui parleremo più avanti, con la quale fu per molto tempo unita sotto il nome di Pteris serrulata Forssk. La somiglianza tra queste due specie induce a pensare che esse derivino da uno stesso progenitore che ritengo ebbe le sue origini nell'altopiano etiopico. Comunque Pteris incompleta è indubbiamente un antico relitto eocenico od oligocenico che ritengo sia pervenuto nell'area mediterranea e nella Macaronesia attraverso il Sahara in tempi precedenti al suo disseccamento.

Diplazium caudatum è bene rappresentato nella Macaronesia, ma altrove vive soltanto in alcune stazioni relitte nelle Sierre di Algeciras in Spagna. Jermy (1964: p. 161) afferma che questa specie «has no close relative on the African mainland» e che (Jermy 1984: p. 414) «its closest allies are in eastern Asia». Tuttavia vi sono in Africa tropicale due specie, Diplazium humbertii (C. Chr.) Pic. Ser. dello Zaire settentrionale, 
Rwanda, Burundi ed Uganda, e Diplazium velaminosum(Diels) Pic. Ser. del Cameroun e del Kenya, ma forse presente anche nell'Africa centrale, che per i sori allantoidei ed altre caratteristiche mostrano una chiara affinità con Diplazium caudatum. Ritengo che quest'ultimo abbia origine comune con le due suddette specie. Data la presenza di una di esse anche nell'A frica tropicale occidentale, Diplazium caudatum potrebbe aver raggiunto l'area mediterranea e la Macaronesia attraverso l'Africa tropicale occidentale, ma ritengo improbabile una migrazione di questo tipo poiché essa si comporta come una specie meno spiccatamente tropicale delle altre due e più atta ad affermarsi in ambiente subtropicale. D'altro lato essa è segnalata nella sola isola di Santo Antão nell'Arcipelago del Capo Verde, mentre vive in tutte le isole nelle Canarie, a Madera ed in 4 delle 7 isole dell'Azzorre (Hansen e Sunding 1985). Pertanto penso che anch'essa seguì la via migratoria del Sahara in tempi eocenici od oligocenici.

Ricordo infine un'altra specie che a mio avviso ebbe origine africana: Vandenboschia speciosa. Essa ha un areale che comprende l'Europa atlantica dall'Irlanda e Gran Bretagna occidentale fino alla Spagna meridionale (Sierre de Algeciras), Italia (fascia basale delle Alpi Apuane) e Macaronesia (excl. Isole del Capo Verde). Questa specie è strettamente affine a Vandenboschia radicans (Sw.) Copel. dell'Africa ed America tropicali; quest'ultima è diploide mentre la prima è tetraploide; quindi Vandenboschia radicans potrebbe essere un progenitore diretto od uno dei progenitori di Vandenboschia speciosa. Un'altra specie affine alle suddette è Vandenboschia gigantea (Bory ex Willd.) Pic. Ser. della Malgassia. Questo rafforza l'ipotesi che Vandenboschia speciosa ebbe i suoi progenitori in Africa, piuttosto che in America, e che essa giunse nell'area mediterranea ed in Macaronesia dall'Africa, sempre attraverso il Sahara ed in tempi paleogenici.

Infine desidero ricordare due specie l'origine delle quali è difficile a stabilire poiché hanno una distribuzione molto ampia. Una è Christella dentata, specie frequente nei tropici e subtropici del Vecchio Mondo e segnalata in varie isole della Macaronesia, ma accantonata nella Regione Mediterranea in poche stazioni relitte in Spagna (provincia di Cadice), Creta e forse anche in Italia, ed in una località della zona submediterranea in Spagna ( provincia di Orense). L'altra è Cyclosorus interruptus, presente nella Regione Mediterranea soltanto in Algeria e Marocco, ma segnalata nei tropici e subtropici di tutto il mondo. Le ricordo qui poiché ambedue sono presenti in Africa tropicale ed è plausibile che la loro diffusione nella Regione Mediterranea avvenne a partire dai territori africani.

L'altra via di migrazione lungo la quale alcune specie di origine africana (Fig. 5) si presume abbiano raggiunto la Regione Mediterranea segue la lunga serie di colline ed altri rilievi montuosi che fiancheggiano ad occidente il Mar Rosso a partire dall'altopiano etiopico. E' presumibile che questa via di diffusione verso nord si rese possibile soltanto quando si verificò l'apertura del Mar Rosso ed il sollevamento delle colline ad esso adiacenti che si pensa avvennero durante il Miocene superiorePliocene inferiore. Pertanto la migrazione lungo questa via interessò piante di origine più recente di quelle che si diffusero attraverso il Sahara, probabilmente le stesse specie che ancor oggi crescono nell'area mediterranea piuttosto che i loro progenitori. 
Inoltre, a differenza di quelle che nel Paleogene seguirono l'altra via di migrazione, queste furono piante tendenzialmente xerofile o comunque meno esigenti nei riguardi dell'umidità. Ritengo anche opportuno osservare che varie pteridofite di questo gruppo, per lo più presenti anche nello Yemen, si diffusero ancor più verso oriente raggiungendo l'India, la Catena Himalayana e lo Yunnan. E' da notare che verosimilmente, in tempi più vicini a noi, questa via fu seguita in senso inverso, dal nord verso l'Africa orientale, in particolare da specie originatesi nell'area mediterranea o nel vicino oriente asiatico.

Ritengo che abbiano origine africana e giunsero nell'area mediterranea attraverso la via di migrazione del Mar Rosso varie specie tra le quali Pteris dentata (Fig. 6) e Pellaea calomelanos. Ambedue sono ampiamente distribuite nelle regioni tropicali e subtropicali africane, la prima anche nello Yemen, la seconda anche in India, ed ambedue relitti nella Regione Mediterranea in una sola area: Pteris dentata nell'isola di Ikaria nel Mar Egeo, Pellaea calomelanos nella Catalogna in Spagna. Ophioglossum polyphyllum è accantonato in due stazioni di rifugio in Europa e Macaronesia, ma largamente rappresentato in Africa tropicale orientale fino al Sudafrica, Arabia, Afghanistan ed India. Notholaena marantae ha un areale molto ampio in Europa, Africa ed Asia (Fig. 7). E' stata ipotizzata una sua origine in Asia da dove si sarebbe diffusa verso occidente, ma il genere Notholaena (s. str.) è rappresentato in Asia soltanto dalla suddetta specie, mentre annovera 5 specie e 2 sottospecie in Africa, una delle quali è Notholaena marantae subsp. subcordata (Cav.) Kunkel della Macaronesia. Appare pertanto probabile una sua origine in Africa ed una sua migrazione lungo la via del Mar Rosso.

Tra le specie della Regione Mediterranea ve ne sono diverse che ebbero origine nell'Europa submediterranea, centrale ed atlantica. Anche se molte di esse si diffusero nella nostra regione durante il Quaternario, alcune a mio avviso erano presenti nella Regione Mediterranea già nel Terziario. Ritengo siano da annoverare tra queste Dryopteris tyrrhena e Dryopteris submontana, due specie scarsamente rappresentate nella Regione Mediterranea dove vivono prevalentemente in zone montane e submontane. Ambedue sono degli allotetraploidi con un progenitore comune e penso si formarono al margine della area mediterranea in zone dove presumibilmente gli areali dei loro progenitori, più o meno ecologicamente isolati, si sovrapponevano od erano limitrofi. Dryopteris tyrrhena ha come progenitori Dryopteris oreades e Dryopteris pallida e si trova in Liguria, Elba, Capraia,Sardegna, Corsica, Alpi Marittime orientali, Cevennes e Sierra Nevada. Dryopteris submontana si è formata dall'ibrido diploide Dryopteris x vidae Fras.-Jenk. et M. Gibby tra Dryopteris pallida e Dryopteris villarii (Bellardi) Woynar ex Schinz et Thellung per duplicazione del corredo cromosomico. Questa ha più ampia distribuzione ed è segnalata anche in Inghilterra, Francia, Europa meridionale fino alla Romania, Caucaso ed Algeria.

Inoltre ricordo Asplenium fissum. Questa è una specie isolata, distribuita prevalentemente nelle zone montane ed altimontane delle Alpi Marittime e nordorientali, Alpi Apuane, Appennino, monti della Penisola Balcanica, Grecia e Bulgaria, ma anche, sia pure raramente, a quote basse. Infine ascrivo a questo gruppo, osservando però che si tratta di una felce con esigenze ambientali nettamente diverse, 


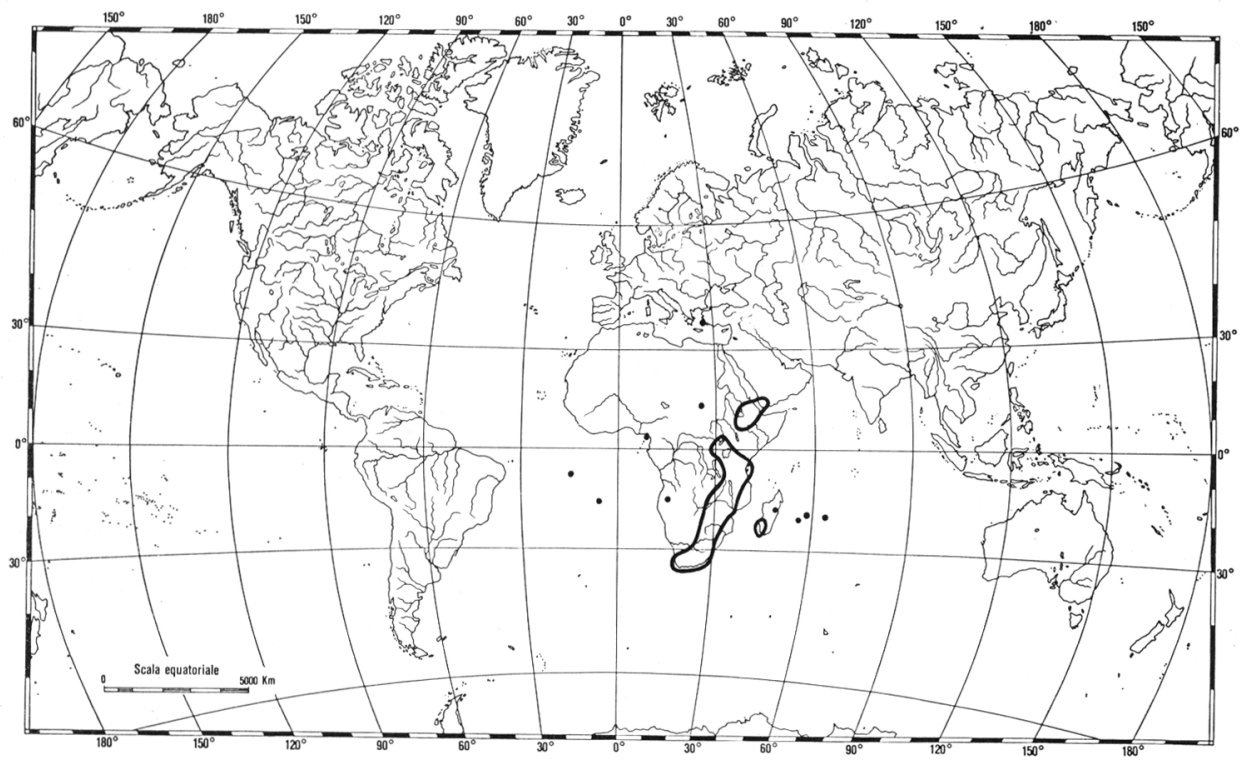

Fig. 6. Areale di Pteris dentata.

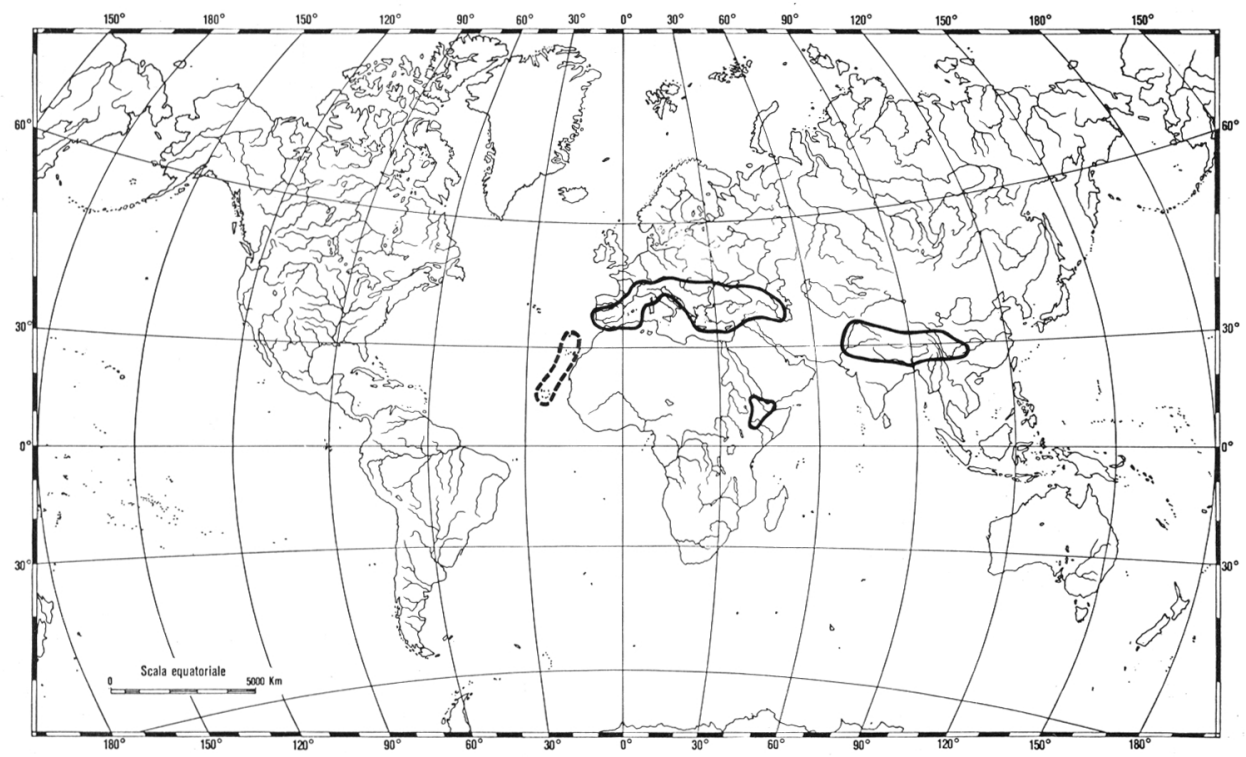

Fig. 7. Areale di Notholaena marantae subsp. marantae —-e subsp. subcordata - - - 
anche Asplenium marinum (Fig. 8), specie tassonomicamente e geneticamente isolata, vivente nelle immediate vicinanze del mare nell'Europa atlantica, Regione Mediterranea e Macaronesia.

Per completare l'indagine sull'origine delle specie presenti nella Regione Mediterranea e territori adiacenti dobbiamo parlare delle pteridofite della Macaronesia. E'stato sostenuto che alcune di esse ebbero origine nelle Canarie od in altre Isole della Macaronesia da dove migrarono poi nella zona mediterranea, ma non condivido tali vedute. Già Page (1973) e Walker (1979) hanno sostenuto, anche senza particolare approfondimento, che le felci della laurisilva oggi presenti nelle Canarie pervennero in quelle isole dall'Europa. In accordo con questi autori ritengo che le specie presenti nelle Canarie, e come relitti nella Regione Mediterranea, di cui abbiamo parlato antecedentemente, come pure varie altre specie di cui tratteremo in seguito, non ebbero origine nelle Canarie ma in Asia, Africa ed Europa. Queste specie facevano parte della pteridoflora che caratterizzava già nell'Eocene-Oligocene le terre emerse oggi comprese nella Regione Mediterranea, allora in gran parte coperta nella Penisola Iberica e nell'Africa mediterranea occidentale da laurisilve. Da queste terre, presumibilmente come rappresentanti erbacei di queste cenosi, cui oggi sono intimamente legate, tali specie raggiunsero le Canarie. Probabilmente la flora che dall'Europa ed Africa trasmigrò nelle Canarie non era costituita soltanto dalle specie della laurisilva mediterranea cenozoica, ma anche da un contingente di specie mesofile e xerofile.

Questa ipotesi sull'origine della pteridoflora delle Canarie trova una valida conferma nel fatto che in base a recenti ricerche geologiche e paleogeografiche (cfr. anche Schmincke 1976) le isole Canarie non sono più antiche dell'Oligocene e non vi sono prove che esse siano emerse dal mare prima del Miocene, quando già da alcuni milioni di anni la laurisilva ricopriva vaste estensioni dei territori occidentali, e forse altre zone ancora, dell'area mediterranea. C'é da aggiungere che si va consolidando tra i geologi la convizione che le isole che formano l'Arcipelago delle Canarie non hanno tutte la stessa origine (Rothe e Schmincke 1968, Schmincke 1976). Mentre le isole occidentali (Gran Canaria, Tenerife, La Gomera, La Palma, Hierro) sarebbero di origine oceanica, Fuerteventura e Lanzarote sarebbero di origine «continentale». Queste rappresenterebbero (Dietz e Sproll 1970, Rona e Nalvalk 1970, Sauer e Rothe 1972) un microcontinente od un frammento sialico continentale che, staccatosi in corrispondenza della «gap» nota in paleogeografia come «Ifni Gap», dal margine marocchino dell'Africa settentrionale, ed andato alla deriva verso occidente con la sua flora e fauna, finì per formare le due isole di Lanzarote e Fuerteventura. Questo spiegherebbe nella maniera più convincente la presenza di uova fossili di struzzo e di un altro ratite aepyornithoide rinvenute nelle calcareniti del Miocene-Pliocene dell'isola di Lanzarote (Rothe 1964, Sauer e Rothe 1972, Sauer 1972, Cracraft 1974). Per quanto ho potuto appurare l'emersione delle Isole del Capo Verde rimonterebbe ad un'età non molto differente da quella delle Canarie, mentre non ho dati per Madera ed Isole Azzorre, ma ritengo che anch'esse siano emerse in tempi troppo recenti per pensare che pteridofite presenti nella Regione Mediterranea ebbero origine in tali isole.

La pteridoflora delle Canarie è assai più ricca di paleoendemismi di quanto lo 
sia quella della Regione Mediterranea, ma alcune specie che mancano in quest'ultima mostrano di aver avuto origine nell'Africa tropicale o nell'Asia sud-occidentale al pari delle specie della Regione Mediterranea; non solo, ma vi sono buone basi per ritenere che per raggiungere le Canarie esse seguirono le stesse vie di migrazione delle pteridofite mediterranee. Queste constatazioni, che riguardano anche le spermatofite (cfr. Davis e Hedge 1971, Bramwell e Richardson 1973), mi portano a pensare che anche alcuni dei relitti e paleoendemismi che sono presenti nelle Canarie ma mancano nell'area mediterranea, appartengano come quelli di cui ho parlato sopra, a quel contingente della pteridoflora che da Europa ed Africa mediterranee migrò nelle Canarie insieme alla laurisilva riuscendo a sopravvivere in queste isole ma non nei paesi mediterranei. Naturalmente ci sono pteridofite, tra quelle che mancano in Europa, che ritengo ebbero origine nelle Canarie od in altre isole della Macaronesia, ma il luogo e l'età della loro formazione sono per alcune di esse incerti.

Dopo aver preso in esame le pteridofite che presumibilmente ebbero origine nei territori adiacenti alla Regione Mediterranea, resta ora da prendere in considerazione quelle specie che si ritiene si formarono nell'area mediterranea.

In primo luogo dobbiamo menzionare gli endemismi. Come ho già precisato nelle pagine precedenti, intendo come tali quelle entità che sono presenti allo stato spontaneo soltanto in particolari zone, di solito limitate in estensione, nell'ambito della Regione Mediterranea. Essi ammontano a 20, corrispondenti al 16\% dell'intera pteridoflora mediterranea. I loro nomi sono qui di seguito elencati.

Isoëtes heldreichii
Isoëtes velata
subsp. perralderiana
subsp. intermedia
subsp. dubia
Isoëtes tiguliana
Isoëtes adspersa
Marsilea batardae
Pilularia minuta
Asplenium balearicum
Asplenium petrarchae
subsp. bivalens

Asplenium majoricum
Asplenium bourgaei
Asplenium jahandiezii
Asplenium aegaeum
Asplenium creticum
Pleurosorus hispanicus
Phyllitis scolopendrium
subsp. antri-jovis
Phyllitopsis hybrida
Dryopteris pallida
subsp. balearica
subsp. libanotica

Asplenium majoricum

Asplenium bourgaei

Asplenium jahandiezii

Asplenium aegaeum

Asplenium creticum

Pleurosorus hispanicus

hyllitis scolopendrium

subsp. antri-jovis

Phyllitopsis hybrida

subsp. balearica

subsp libanotica

In base all'affinità con le altre specie del gruppo tassonomico cui esse appartengono, in base alla loro distribuzione geografica, ed alle loro caratteristiche citologiche, di cui ho parlato prima, è facile accertare che la maggior parte di esse sono degli endemismi che risalgono a tempi assai remoti, che possiamo chiamare paleoendemismi usando questo termine in senso lato. Tuttavia restano molti interrogativi a quale tipo di endemismi alcune di esse potrebbero essere riferite quando si seguisse l'inquadramento di Favarger e Contandriopoulos (1961).

Fa parte dei paleoendemismi anche Pleurosorus hispanicus, che ritengo specie a sé stante, distribuito nella Spagna meridionale, Marocco ed Algeria. Esso appartiene 


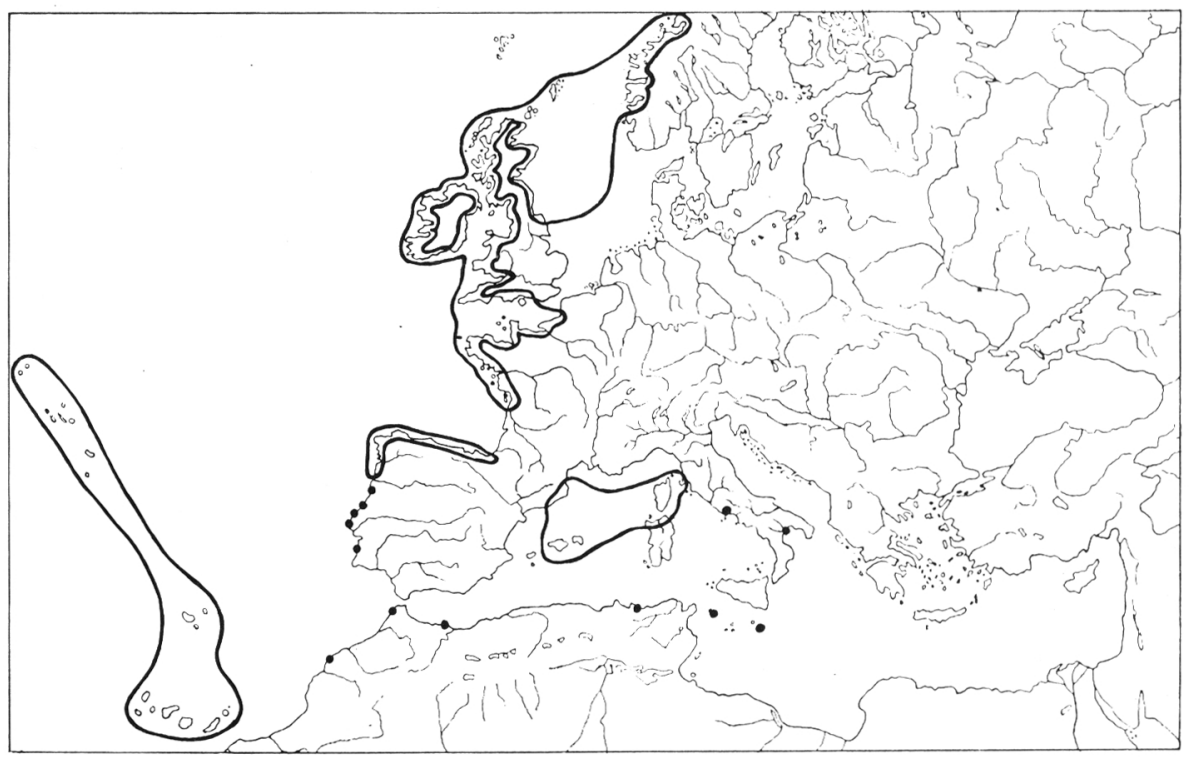

Fig. 8. Areale di Asplenium marinum.

ad un genere che consiste della suddetta specie, di un'altra con due sottospecie, $P$. rutifolius (R. Br.) Fée subsp. rutifolius dell'Australia e Nuova Zelanda e $P$. rutifolius subsp. subglandulosus (Hook. et Grev.) Pic. Ser. ${ }^{*}$ dell'Australia, e di una terza, $P$. papaverifolius (Kunze) Fée del Cile e dell'Argentina. Una tale distribuzione (Fig. 9) è molto strana ed interessante ma difficile a spiegare. Pleurosorus è da taluni ritenuto un discendente exindusiato abbastanza recente di Asplenium. Ho già tempo addietro espresso l'opinione che questo genere sia «an ancient offshoot of primitive Aspleniaceae» (Pichi Sermolli 1979: p. 214). Pur trattando Pleurosorus come un sottogenere di Asplenium, anche Salvo, Prada e Diaz (1982) ritengono che esso sia una linea abbastanza arcaica delle Aspleniaceae, indipendente da quella del sottogenere Asplenium nel quale essi includono anche Ceterach e Phyllitis. La strana distribuzione di Pleurosorus potrebbe essere spiegata ammettendo che questo genere risale alla Gondwana quando le terre in cui oggi cresce formavano un'unica massa terrestre, ma in tal caso dovremmo far risalire la sua origine addirittura al Triassico, un tempo troppo remoto perché questa ipotesi possa essere accettata senza riserve. Pertanto a mio avviso il problema dell'origine di Pleurosorus rimane aperto. nov. (basion.: Gymnogramma subglandulosa Hook. et Grev. Icon. Fil. 1: tav. 91. 1828). 


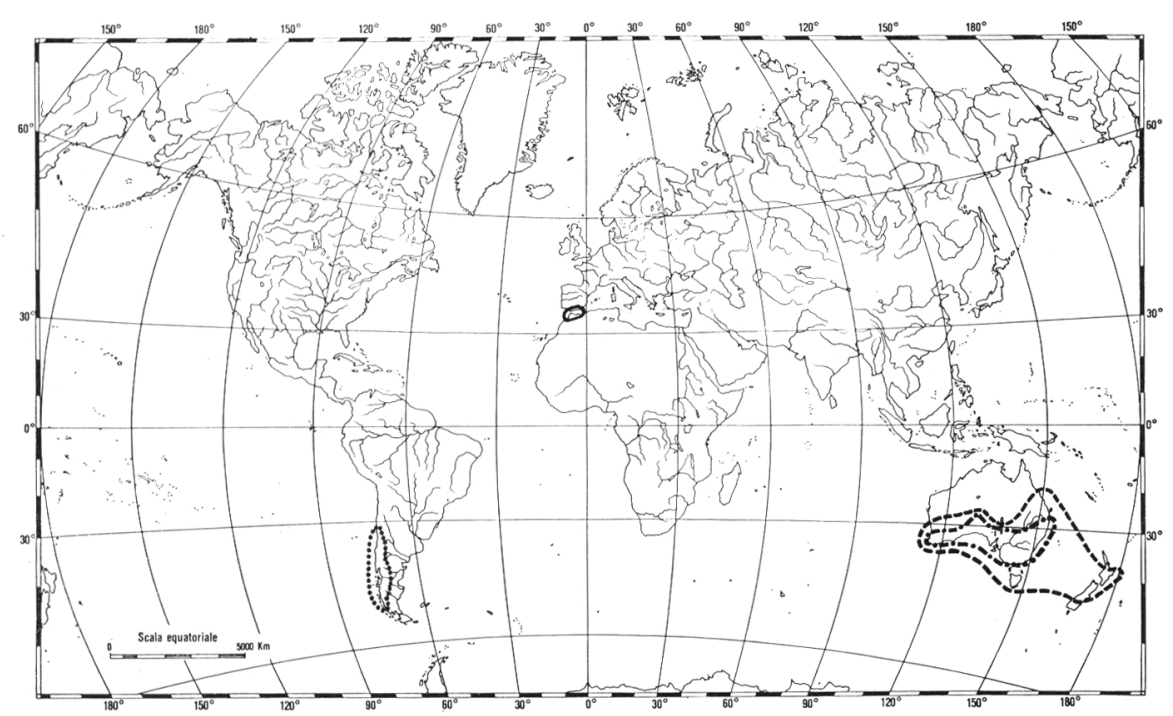

Fig. 9. Areale del genere Pleurosorus: P. hispanicus — ; P. rutifolius subsp. rutifolius - - - P. rutifolius subsp. subglandulosus - - - - - P. papaverifolius

Un endemismo di recente formazione è il genere Phyllitopsis, costituito da una sola specie, Phyllitopsis hybrida, delle isole del Quarnaro in Yugoslavia, al limite settentrionale della Regione Mediterranea. Questa specie si è formata da un ibrido diploide intergenerico tra Ceterach officinarum susp. bivalens e Phyllitis sagittata in seguito a duplicazione del suo corredo cromosomico. Questo processo ormai ben noto ha portato alla formazione di una nuova specie allotetraploide tra due generi diversi che rappresenta il tipo di un nuovo genere distinto sia da Ceterach come da Phyllitis. Nella stessa zona, sebbene non nella stessa località in cui vive Phyllitopsis hybrida si trovano anche i suoi progenitori diploidi e questo induce a ritenere che questo nuovo genere si sia formato in tempi abbastanza recenti (cfr. Pichi Sermolli 1990), ma non certo in tempi storici come qualcuno ha sostenuto.

Oltre agli endemismi fanno parte della pteridoflora della Regione Mediterranea anche specie e gruppi di specie che ebbero il loro centro di formazione nell'area mediterranea nel Cenozoico e che più tardi si diffusero in territori adiacenti e talora più oltre. Taluni di essi per il loro areale ridotto potrebbero anche essere considerati come endemismi biregionali.

Varie pteridofite a mio avviso sono da riferire a questo gruppo di entità di origine cenozoica e ritengo di dover menzionare le seguenti. In primo luogo ricordo Asplenium hemionitis, una specie isolata senza chiare affinità sistematiche salvo una certa somiglianza morfologica con Asplenium lastii C. Chr. del Madagascar, pur esso a foglie semplici. La sua presenza nella Regione Mediterranea è limitata al Marocco ed Algeria, ma la specie cresce anche in Portogallo (Sierre di Sintra e Mafra) e nella 
Macaronesia. A mio avviso Asplenium hemionitis è una specie antica formatasi nell'Oligocene, se non prima, facente parte della laurisilva che allora copriva gran parte del settore occidentale della Regione Mediterranea.

Ricordo inoltre le seguenti specie: Phyllitis sagittata presente (Fig. 10) in quasi tutta la Regione Mediterranea, normalmente in stazioni non lontane dal mare, ma anche in poche altre località al di fuori di essa, relitti della trasgressione pliocenica quando il mare penetrava profondamente nelle pianure pedemontane; Selaginella denticulata distribuita (Fig. 11) pure essa in tutta la Regione Mediterranea, ma presente anche in Madera e nelle Canarie; Asplenium petrarchae presente nella Regione Mediterranea con il citotipo diploide (subsp. bivalens) segnalato di poche località della Spagna meridionale ed il citotipo autotetraploide (subsp. petrarchae) distribuito con maggiore o minore frequenza in tutti e tre i settori mediterranei ed inoltre nei territori limitrofi submediterranei ed in quelli aridi del Nordafrica; Asplenium seelosii subsp. glabrum presente in varie località disgiunte prevalentemente montane della Spagna mediterranea e submediterranea, nei Pirenei e nel Medio Atlante; e Cystopteris viridula, una specie ritenuta erroneamente conspecifica con Cystopteris diaphana (Bory) Blasdell della Malgassia, non sufficientemente studiata dal punto di vista tassonomico e di cui non è stata bene accertata la distribuzione, tuttavia presente nella Regione Mediterranea, nella zona submediterranea ed atlantica dell'Europa ed in Macaronesia; la ricordo prevalentemente allo scopo di stimolarne lo studio.

Rimane infine da accennare ai generi Cheilanthes e Cosentinia. Date le tendenze xerofile di queste specie, sono propenso a pensare che la loro origine non si spinge indietro nel tempo oltre l'Oligocene. Come ebbi modo di mettere in evidenza nella mia relazione al precedente Simposio di Botanica Crittogamica a Madrid nel 1987 (Pichi Sermolli 1990) le specie di Cheilanthes presenti nell'area mediterranea formano un gruppo omogeneo di diploidi e tetraploidi imparentati tra loro e tutti quanti presenti nella Regione Mediterranea. Dette constatazioni mi inducono a pensare che questo gruppo di specie venne formandosi ed evolvendosi nella Regione Mediterranea. I loro nomi e le interrelazioni delle specie diploidi con quelle tetraploidi cui esse dettero origine, prima con la formazione degli ibridi diploidi ed in seguito con la duplicazione del loro corredo cromosomico, sono illustrati nella Figura 12. E' interessante notare che i diploidi sono 4 ed essi avrebbero potuto dare origine a 6 allotetraploidi, mentre ne sono noti 3, la mancata formazione dei tre rimanenti allotetraploidi (HiHiPePe, $\mathrm{HiHiPuPu}, \mathrm{PePePuPu}$ ) è presumibilmente imputabile a barriere geografiche interposte tra gli areali dei progenitori diploidi o forse ad un impedimento epiontologico. E' da notare altresì che tutti e tre gli allotetraploidi sono presenti nella Macaronesia e che uno di essi, Cheilanthes acrostica, ha una più ampia diffusione raggiungendo verso sud-ovest le isole del Capo Verde, verso sud-est i massicci dell'Hoggar e Tibesti, l'Etiopia e lo Yemen e verso est l'Iraq, il Daghistan, l'Iran e più oltre il Kashmir. In base a ricerche precedenti (Pichi Sermolli 1990), ritengo che questa specie ebbe il suo primo centro di formazione nel settore orientale della Regione Mediterranea.

Cosentinia vellea è l'unica specie finora nota del genere e di essa si conoscono il diploide (subsp. bivalens) segnalato in poche località della Spagna e di tre isole delle 


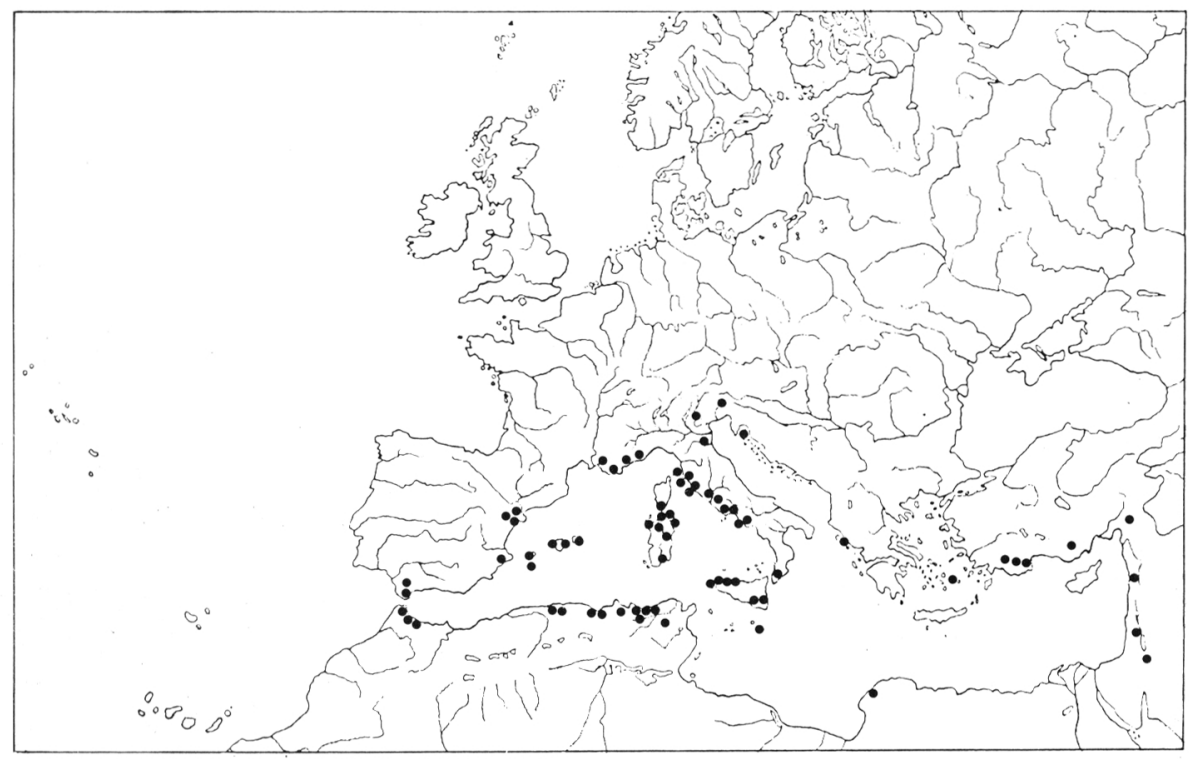

Fig. 10. Areale di Phyllitis sagittata

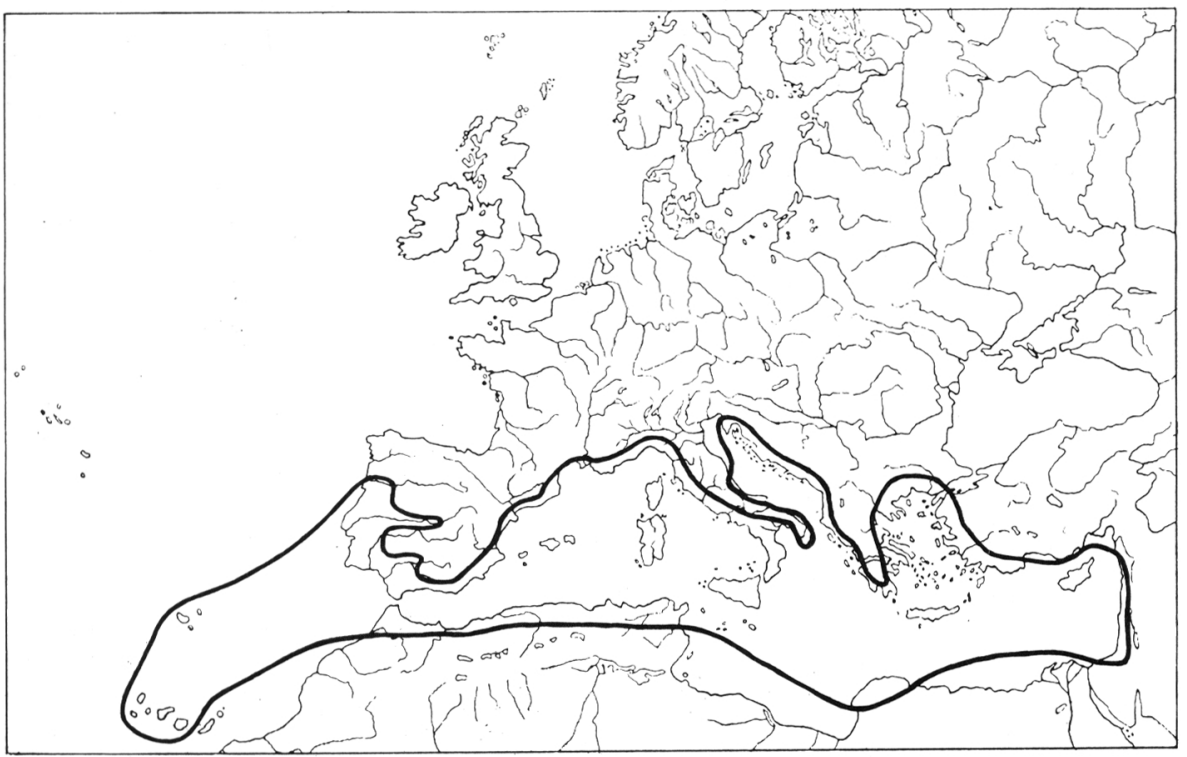

Fig. 11. Areale di Selaginella denticulata. 


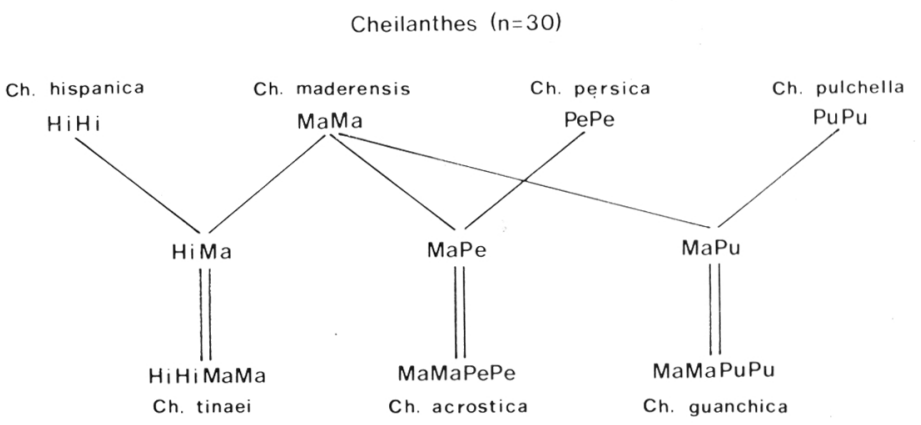

Fig. 12. Interrelazioni genomiche delle specie del genere Cheilanthes presenti nelle Regione Mediterranea e Macaronesica.

Canarie (La Palma, Tenerife ed Hierro) e l'allotetraploide (subsp. vellea) largamente distribuito nella Regione Mediterranea (con qualche stazione anche nell'Europa submediterranea), in Madera, nelle isole Canarie e del Capo Verde, Marocco, Algeria, Tunisia, Libia, Tibesti, Nubia, Etiopia settentrionale, Arabia, Sinai, Iran meridionale, Afghanistan e Kashmir. Quando la specie era imperfettamente nota, avevo ipotizzato una origine asiatica di essa, ma la presenza della subsp. bivalens nella parte occidentale della Regione Mediterranea e nelle Canarie mi fa invece ritenere che anche Cosentina vellea si originò nella Regione Mediterranea donde si diffuse ampiamente verso ovest, sud ed est.

Forse Cosentinia vellea, come pure Cheilanthes acrostica, seguirono nella loro diffusione verso sud quelle vie di migrazione che in senso opposto ed in tempi più antichi avevano permesso alle specie di origine africana od ai loro predecessori di diffondersi dai massicci dell'Africa orientale alla Regione Mediterranea.

Per rendere più completa l'analisi delle specie che ritengo fossero già presenti nella Regione Mediterranea nel Terziario, penso sia opportuno accennare ad alcune pteridofite che per la loro ampia distribuzione non forniscono elementi per presupporre in quale regione esse ebbero origine.

Botrychium lunaria è una specie molto antica. Finora ben poco era noto della storia paleontologica del gruppo di pteridofite (Ophioglossopsida) cui la specie appartiene. E' recente la scoperta in Canada di una specie fossile del Paleocene assegnata al genere Botrychium (Rothwell et al. 1989), ma a mio avviso seguendo la classificazione da me adottata nel «Tentamen» (Pichi Sermolli 1977) essa è da riferire al genere Botrypus includendo in esso Japanobotrychium come sottogenere, che è trattato come genere a sé stante da Kato (1987). Questi resti fossili mostrano caratteristiche morfologiche molto simili a quelle delle specie viventi e ci testimoniano che questo genere aveva già raggiunto nel Paleocene un livello evolutivo molto avanzato. Anche se questi fossili non ci confermano la presunta antichità delle Ophioglossopsida, ci indicano in maniera chiara che esse sono indubbiamente assai più antiche del Paleocene. Botrychium lunaria ha un areale che dal $74^{\circ}$ parallelo in Groenlandia si estende verso sud fino al $28^{\circ}$ parallelo nell'Himalaya ed ancor più a sud 
fino al Cile e Patagonia, Australia sud-orientale, Tasmania e Nuova Zelanda meridionale. Questo vasto areale ci consente soltanto di stabilire che la specie ebbe origine nell'emisfero boreale ma al tempo stesso ci permette, oggi che abbiamo la prova che il genere risale per lo meno al Mesozoico, di ipotizzare che i suoi antenati potevano far parte della flora della Laurasia.

Psilotum nudum è una specie pantropicale, ma si estende anche in zone temperate specialmente verso sud. La specie raggiunge il suo limite settentrionale in Europa nelle Sierre di Algeciras in Spagna, in Asia in Giappone e nel Nord America nella Carolina del Sud. Senza volere precisare dove la specie si evolse, ritengo si possa ipotizzare che essa ebbe origine nell'emisfero meridionale. Malgrado che ben poco si sappia sul passato paleontologico delle Psilotaceae, esse sono indubbiamente un gruppo molto antico e non è da escludere che Psilotum nudum ebbe origine da progenitori facenti parte della flora della Gondwana.

Anogramma leptophylla è una specie caratterizzata, fra l'altro, dallo sporofito annuale e la sopravvivenza del gametofito, provvisto di organi tuberiformi, per più di una stagione vegetativa. Essa ha una distribuzione molto estesa, con ampie disgiunzioni; vive in Europa atlantica e submediterranea, Regione Mediterranea, Iran, India sudoccidentale, Giava, Australia sud-orientale, Tasmania e Nuova Zelanda; in Africa tropicale nord-orientale ed orientale, Madagascar ed Africa australe; nell'isola di Ascension; ed in America dal Messico al Peru. Appare problematico accertare dove essa si formò, ma la sua distribuzione palesa un'origine nell'Emisfero meridionale, confermata anche dal fatto che 4 delle 6 specie che costituiscono il genere Anogramma sono distribuite nell'America centrale e meridionale. Penso che la specie, dato il suo ampio areale, sia di origine cenozoica se non più remota.

Accanto alle specie delle quali ho finora parlato, vi sono numerose pteridofite dell'Europa, Asia ed America settentrionale che probabilmente ebbero origine nel Terziario ed ebbero possibilità di avere interscambi grazie alle connessioni tra le due masse continentali Euroasiatica ed Americana. Tuttavia esse in grande maggioranza raggiunsero la Regione Mediterranea soltanto durante le glaciazioni quaternarie e rappresentano il contingente meno tipico della pteridoflora mediterranea. La vasta distribuzione di queste specie da un lato e lo scarso aiuto che esse ci possono offrire per lo studio dell'origine della pteridoflora mediterranea m'inducono ad astenermi da prendere in esame anche queste specie.

$$
* * *
$$

Il quadro degli avvenimenti paleogeografici e paleoclimatici di maggiore interesse biologico, succedutisi nella Regione Mediterranea, che ho tracciato nei suoi lineamenti essenziali nelle pagine precedenti, mi spinge a fare una breve sintesi della storia del popolamento vegetale.

La pteridoflora delle terre corrispondenti all'area mediterranea attuale, durante il Mesozoico ed il Paleocene era presumibilmente costituita da specie appartenenti alle famiglie primitive delle quali ancor oggi sopravvivono rappresentanti nelle regioni equatoriali. 
Più tardi durante l'Eocene queste terre erano verosimilmente coperte da una foresta di tipo tropicale favorevole alla diffusione ed evoluzione delle pteridofite igrofile, soprattutto là dove, lungo la Mesogea e la Neotetide o lungo l'Atlantico, la vicinanza del mare garantiva un clima oceanico. Nell'Oligocene, pur persistendo condizioni oceaniche, probabilmente in seguito ad un raffreddamento del clima, la flora e la vegetazione andarono evolvendosi verso un tipo subtropicale fino a dar luogo ad un popolamento vegetale diverso, per lo più rappresentato dalla laurisilva mediterranea. Parlo di laurisilva mediterranea e non di laurisilva canaria,come vari autori la chiamano, poiché sono convinto che la laurisilva oggi presente nelle Canarie ed in altre isole della Macaronesia, non molto diversifica dalla laurisilva mediterranea oligocenica che dall'Europa ed Africa settentrionale trasmigrò nelle Isole Canarie. Qui, grazie alle particolari e favorevoli condizioni ambientali offerte alla vita vegetale dalla posizione geografica e dalle caratteristiche climatiche ed orografiche di queste isole, non solo riuscì a sopravvivere ai mutamenti climatici pleistocenici e a giungere fino a noi, ma anche ad arricchirsi di nuove entità autoctone.

I notevoli cambiamenti climatici che accompagnarono i grandi eventi geologici avvenuti nel Miocene, soprattutto nel Messiniano, portarono un profondo sconvolgimento nella flora dell'area mediterranea. Fu così che nel volgere di pochi milioni di anni, l'antica flora oceanica fu soggetta ad un notevole impoverimento e la laurisilva andò in gran parte estinguendosi nella Regione Mediterranea, riuscendo a sopravvivere soltanto nella Macaronesia.Tuttavia varie piante tra cui alcune pteridofite che ne facevano parte sono giunte fino a noi in stazioni relitte poste nella parte occidentale della Penisola Iberica ed in Marocco. Così la laurisilva lasciò il posto a steppe, praterie ed altre cenosi semi-aride, alternate a foreste mesofile lungo le rive dei laghi e fiumi, e nelle vallate pedemontane.

Altre trasformazioni ed un ulteriore impoverimento dell'antica flora cenozoica oceanica avvennero nel Pleistocene con l'invasione dell'area mediterranea da parte delle piante provenienti dall'Europa media e settentrionale sotto la spinta delle mutate condizioni ambientali verificatesi durante le glaciazioni.

La flora pteridologica delle terre che circondano il Mediterraneo, sebbene notevolmente impoverita rispetto a quella di un tempo, ha oggi una sua netta originalità bene distinguendosi da quella delle zone limitrofe del resto d'Europa , Asia ed Africa. Molte sue caratteristiche confermano infatti l'oportunità di riconoscere l'area mediterranea come una regione floristica autonoma, non ultime tra queste l'esistenza di molti endemismi e relitti accantonati in limitate zone di rifugio d'inestimabile valore naturalistico delle quali mi auguro che l'uomo, malgrado le molte difficoltà, riuscirà a garantire la conservazione.

\section{RINGRAZIAMENTI}

Rivolgo i miei più sinceri ringraziamenti ai professori A. Azzaroli, M. Boccaletti e V. Bortolotti del Dipartimento di Scienze della Terra dell'Università di Firenze per il valido aiuto ricevuto nel redigere la parte della mia relazione concernente la paleogeografia della zona mediterranea. 


\section{RIFERIMENTI BIBLIOGRAFICI}

BANDY, O.L. -1973- Chronology and paleoenvironmental trends, Late Miocene-Early Pliocene, western Mediterranean, in Drooger, C.W. (ed.), 1973: pp. 21-25. fig.1-3.

BENDA, L.-1973-Late Miocene sporomorph assemblages from the Mediterranean and their possible paleoclimatological implications, in Drooger, C.W. (ed.), 1973:pp. 256-259.

BERRY, E.W. - 1930- Revision of the Lower Eocene Wilcox flora, the Southeastern States with description of new species, chiefly from Tennessee and Kentucky.U.S. Department of Interior Geol. Surv. Professional Pap., 156: 1-196. fig. 1-32. tav. 1-50.

BERTOLANI MARCHETTI, D. \& M.B. CITA -1975- Studi sul Pliocene e sugli strati di passaggio dal Miocene al Pliocene. VII. Palynological investigations on Late Messinian sediments recorded at DSDP Site 132(Tyrrhenian Basin) and their bearing on the deep basin diseccation model. Rivista Ital. Paleontol. Stratigr., 81 : 281-308. tav. 37-40.

BOCQUET, G., B. WIDLER \& H. KIEFER -1978- The Messinian model- A new outlook for the floristics and systematics of the Mediterranean area. Candollea, 33:269-287. fig. 1-2.

BORGEN , L. -1969- Chromosome numbers of vascular plants from the Canary Islands, with special reference to the occurrence of polyploidy. Nytt Mag. Bot., 16: 81-121. fig. 1-101.

BRAMWELL, D. -1972- Endemism in the flora of the Canary Islands. in Valentine, D. H. (ed.), Taxonomy and evolution. pp. 141-159. fig. 1-11. London (Acad. Press.).

BRAMWELL, D. -1976- The endemic flora of the Canary Islands; distribution, relationships and phytogeography. In Kunkel G. (ed.), 1976: pp. 207-240. fig. 1-20.

BRAMWELL, D. - 1986 - Contribución a la geografía de las Islas Canarias. Bot. Macar. 14: 3-34. fig. 1-24. ('1985').

BRAMWELL, D. \& I.B.K. RICHARDSON -1973-Floristic connections between Macaronesia and the East Mediterranean Region. Monogr. Biol. Canar. , 4: 118-125. fig. 1-4.

BROWNSEY, P. J. \& J.D. LOVIS -1987- Chromosome numbers for the New Zealand species of Psilotum and Tmesipteris, and the phylogenetic relationship of the Psilotales. New Zealand Journ. Bot., 25: 439-454. fig. 1-2.

BRUNEAU DE MIRÉ, P. \& P. QUÉZEL -1959- Sur la présence de la bruyére en arbre (Erica arborea L.) sur les sommets de l'Emi Koussi (Massif du Tibesti). Compt. Rend. Sommaire Séances Soc. Biogéogr., 315: 66-70.

CASTROVIEJO, S., M. LAÍNZ, G. LÓPEZ GONZÁLEZ, P. MONTSERRAT, F. MUÑOZ GARMENDÍA, J. PAIVA \& L. VILLAR (eds.) -1986- Flora Ibérica. Plantas vasculares de la península Ibérica e Islas Baleares. Vol. I. Lycopodiaceae - Papaveraceae. Madrid (Real Jardín Botánico, C.S.I.C., Impr. Grafica 82. S.A.).

CITA, M.B. \& C. CORSELLI -1990- Messinian paleogeography and erosional surfaces in Italy: an overview. Palaeogeogr. Palaeoclimat. Palaeoecol., 77: 67-82. fig. 1-17.

CRACRAFT, J. -1974- Phylogeny and evolution of the ratite birds. Ibis, 116:494-531. fig. 1-10.

CROIZAT, L. -1958- Panbiogeography or an introductory synthesis of Zoogeography, Phytogeography and Geology; with notes on evolution, systematics, ecology, anthropology, etc. Vol. 1, 2a, 2b. Denver (Salland).

CROIZAT, L. -1965- Cenni sulla panbiogeografia delle Isole Canarie. Atti Ist. Bot. Univ. Pavia. ser. 6. 1: 53-98.fig. 1-7.

CROIZAT, L. - 1968- Introduction raisonnée à la biogeographie de l'Afrique. Mem. Soc. Brot. 20: 1-451. fig. 1-47.

DAVIS, P.H. (ed.) -1965-Flora of Turkey and East Aagean Islands. Vol. 1. Edinburgh (Univ. Press). 
DA VIS, P.H. \& I.C. HEDGE - 1971- Floristic links between N.W. Africa and S.W. Asia. Ann. Naturh. Mus. Wien, 75: 43-57 . fig. 1-7.

DIETZ, R.S. \& W.P. SPROLL -1970- East Canary Islands as a microcontinent within the Africa -North America continental drift fit. Nature, 226: 1043-1045. fig. 1.

DROOGER, C.W. (ed.) -1973-Messinian events in the Mediterranean. Geodinamics Scientific Report No. 7. Amsterdam (North Holland Co.).

EMBERGER, L., H. GAUSSEN, M. KASSAS \& A. DE PHILIPPIS -1963-Carte bioclimatique de la Région Mediterranéenne. Bioclimatic map of the Mediterranean Region. (Echelle 1:5.000.000, Scale 1: 5.000.000). [ Et] Notice explicative; Explanatory notes. UNESCOFAO (Recherches sur la Zone aride- Arid zone research. XXI). Paris.

FAVARGER, C. \& J. CONTANDRIOPOULOS -1961- Essai sur l'endémisme. Ber. Schweiz Bot. Ges. (Bull. Soc. Bot. Suisse), 71: 384-408.

GOOD, R. -1953- The geography of the flowering plants. ed. 2. London (Longmans, Green).

GREUTER, W., H.M. BURDET \& G. LONG (ed.)-1984-Med-Checklist. 1. Pteridophyta (ed.2) Gymnospermae Dicotyledones (Acanthaceae-Cneoraceae). Genève.

GVIRTZMAN, A. \& B. BUCHBINDER -1977- The desiccation events in the eastern Mediterranean during Messinian times as compared with other Miocene desiccation events in the basins around the Mediterranean. Proc. Int. Symp. Split. 1976: 411-420. fig. 1-2.

HAGERUP, 0. -1932- Über Polyploidie in Beziehung zu Klima, Ökologie und Phylogenie. Chromosomenzahlen aus Timbuktu. Hereditas, 16: 19-40. fig. 1-34.

HANSEN, A. \& P, SUNDING -1985-Flora of Macaronesia. Checklist of vascular plants. 3 revised edition. Sommmerfeltia, 1: 1-167.

HARRIS, T.M. -1961-The Yorkshire Jurassicflora.I. Thallophyta-Pteridophyta. London (Brit. Mus.).

HEDBERG, O., I. HEDBERG, B. JONSELL, L. JUNELL, N. LUNDQVIST \& O. OLSSON -1961 - Monograph of the genus Canarina L. (Campanulaceae). Svensk Bot. Tidskr., 55: 17-62. tav. 1-4. fig. 1-21.

HOLTTUM, R.E. -1963-Cyatheaceae. Flora Malesiana, Sér. 2, Pteridophyta. Vol. 1(2): 65176. fig. 1-34.

JERMY, A.C. -1964- Two species of Diplazium in Europe. Brit. Fern Gaz., 9(5).: 160-162.

JERMY , A.C. -1984- Origin and distribution of Pteridophyta in the Mediterranean area. Webbia, 38: 397-416. fig. 1-3.

KATO, M. -1987- A phylogenetic classification of Ophioglossaceae. Gard. Bull. Singapore, $40: 1-14$. fig. $1-4$.

KLEOPOV, YU. D. -1972- Carta delle Regioni floristiche del territorio Eurosiribico, in Zangheri, P., 1972. Geobotanica. Enciclopedia Italiana delle Scienze: Gli esseri viventi 2: 374-484. 177 fig. (cfr. p. 392). Novara (Ist. Geogr. De Agostini).

KUNKEL, G. (ed.) -1976- Biogeography and ecology in the Canary Islands. (Monographiae Biologicae vol. 30). The Hague (Yunk).

LALANDE, P., F. BAGNOULS \& H. GAUSSEN -1969- Carte de la végetation de la région méditerranéenne. Vegetation map of the Mediterranean region. (1/5.000.000). [Et] Notice explicative. Explanatory notes. UNESCO-FAO. (Recherches sur la zone aride-Arid zone research XXX).Paris.

LARSEN, K. -1960- Cytological and experimental studies on the flowering plants of the Canary Islands. Biol. Skr., 11(3): 1-60. tav. 1-6. fig. 1-16.

LARSEN, K. -1963-Contribution to the cytology of the endemic Canarian elements.II. Bot. Notiser, 116: 409-424. fig. 1-24. 
LÖVE, A. \& D. LÖVE - 1943- The significance of differences in the distribution of diploids and polyploids. Hereditas, 29: 145-163.

LÖVE, A. \& D. LÖVE -1948- Chromosome numbers of northern plant species. Iceland Univ. Inst. App. Sci. Dep. Agric. Rep. Ser. B. 3: 1-131.

LOVIS, J.D. -1977- Evolutionary patterns and processes in Ferns. Advances Bot. Res., 4: 229415. fig. 1-23.

MANTON, I. -1969- Evolutionary mechanism in tropical ferns. Biol. Journ. Linn. Soc. 1:219222.

MARIOTTI LIPPI, M. -1989- Ricerche palinologiche sul Messiniano di Eraclea Minoa (AG.) nel quadro paleofloristico e paleovegetazionale del tardo Miocene italiano. Webbia, 43: 169-199. fig. 1-5. tav. 1-3.

MATTICK, F. -1964- Übersicht über die Florenreiche und Florengebiete der Erde. in Melchior, H. (ed.), A. Engler's Syllabus der Pflanzenfamilien . ed. 12. Band II. 626-629. 1 Karte . Berlin (Borntraeger).

MEUSEL, H. -1943-Vergleichende Arealkunde. 2 Vol. Berlin.

MEUSEL, H. -1962- Die mediterran-mitteleuropäischen Florenbeziekungen auf Grund vergleichender chorologischer Untersuchungen. Ber. Deutsch. Bot. Ges. , 75: 107-118. fig. 1-8.

MEUSEL, H., E. JÄGER \& E. WEINERT -1965-Vergleichende Chorologie der zentraleuropäischen Flora. Jena (G. Fischer Verlag.).

PAGE, C.N. -1973-Ferns, polyploids, and their bearing on the evolution of the Canarian flora. Monogr. Biol. Canar. , 4: 83-88.

PARRIS, B. S. \& C.R. FRASER-JENKINS -1980- A provisional checklist of Turkish Pteridophyta. Notes Roy. Bot. Gard. Edinburgh, 38: 273-281. 1 fig.

PICHI SERMOLLI, R.E.G. -1977- Tentamen pteridophytorum genera in taxonomicum ordinem redigendi. Webbia , 31: 313-512. fig. 1-20.

PICHI SERMOLLI, R.E.G. -1979-A survey of the pteridological flora of the Mediterranean Region. Webbia, 34: 175-242. fig. 1-26.

PICHI SERMOLLI, R.E.G. -1990- Speciazione e distribuzione geografica nelle Pteridophyta. Anales Jard. Bot. Madrid., 46:489-518. fig. 1-19. ('1989').

PICHI SERMOLLI, R.E.G. \& M.P. BIZZARRI -1978- The botanical collections (Pteridophyta and Spermatophyta) of the AMF Mares- G. R. S. T. S. Expedition to Patagonia, Tierra del Fuego and Antarctica. Webbia, 32: 455-534. fig. 1-10. tav. 1-13.

PICHI SERMOLLI, R.E.G., L. ESPAÑA \& A.E. SALVO -1988- El valor biogeográfico de la pteridoflora iberica. Lazaroa, 10: 187-205. fig. 1-5. ('1987-88').

QUÉZEL, P. -1978- Analysis of the flora of Mediterranean and Saharan Africa. Ann. Missouri Bot. Gard., 65: 479-534. fig. 1-11.

RIKLI, M. -1942-1948- Das Pflanzenkleid der Mittelmeerländer. 3 Vol. Bern (H. Huber).

REESE, G. -1957- Über die Polyploidiespektren in der nordsaharischen Wüstenflora. Flora, 144: 598-634. fig. 1-15.

REESE, G. -1958- Polyploidie und Verbreitung. Zeitschr. Bot. 46: 339-354. fig. 1.

RONA, P.A. \& A.J. NALWALK - 1970- Post-early Pliocene unconformity on Fuerteventura, Canary Islands. Geol. Soc. Amer. Bull., 81: 2117-2122. fig. 1-4.

ROTHE, R. -1964- Fossile Strausseneier auf Lanzarote. Natur Mus., 94: 175-187. fig. 1-8.

ROTHE, P. \& H. U. SCHMINCKE - 1968- Contrasting origins of the eastern western islands of the Canarian Archipelago. Nature, 218: 1152-1154. fig. 1-2.

ROTHWELL, G.W. \& R.A. STOKEY -1989- Fossil Ophioglossales in the Paleocene of the western North America. Amer. Journ Bot. , 76 : 637-644. fig. 1-19. 
SALVO, A.E., C. PRADA \& T. DIAZ -1982- Revision del género Asplenium L. Subgénero Pleurosorus (Fée) Salvo, Prada \& Diaz. Candollea, 37: 457-484. fig. 1-11.

SAUER, E.G.F. -1972- Ratite eggshells and phylogenetic questions. Bonn. Zool. Beitr., 23: 348. fig. 1-24.

SAUER, E.G.F. \& P.ROTHE - 1972- Ratite eggshells from Lanzarote, Canary Islands. Science, 176: 43-45. fig. $1-2$.

SCHMINCKE, H.U. -1968- Pliozäne, subtropische vegetation auf Gran Canaria. Naturwiss., 55: $185-186$.

SCHMINKE, H.U. -1976- The geology of the Canary Islands. in Kunkel, G. (ed.), 1976. pp. 67-184. fig. 1-72.

STEBBINS, G.L. -1942- Polyploid complexes in relation to ecology and the history of floras. Amer. Naturalist, 76: 36-45. fig. 1-2.

TAKHTAJAN, A. -1986- Floristic Regions of the World. Berkeley (Univ. Calif. Press)

TISCHLER, G. - 1935- Die Bedeutung der Polyploidie für die Verbreitung der Angiospermen, erlaütert an den Arten Schleswig-Holsteins, mit Ausblicken auf andere Florengebiete. Bot. Jahr. Syst., 67: 1-36.

TREVISAN, L. -1967- Pollini fossili del Miocene superiore nei tripoli di Gabbro (Toscana). Palaeontografía Ital. , 62: 1-78. fig. 1-8. tav. 136.

VAN VALEN, L. \& R.E. SLOAN -1972- Ecology and extintion of the Dinosaurus. Abstracts, Résumés. 24th Int. Geol. Congr. Montreal, Canada, p. 247.

WALKER, T.G. -1979- The cytogenetics of Ferns. in Dyer, A. F. (ed.), The experimental biology of Ferns. 87-132. fig. 1-8. (Experimental Botany Vol. 19) London (Acad. Press).

WHITE, F. (ed.) -1983- UNESCO/AETFAT/UNSO. Vegetation map of Africa (Scale 1:5.000.000) compiled by F. White, on behalf of the AETFAT Vegetation Map Committee (A. Aubreville, L. A. G. Barbosa, L. E. Codd, P. Duvigneaud, H. Gaussen, R. E. G. Pichi Sermolli, H. Wild, F. White). 4 sheets. Paris (UNESCO).

WHITE, R.A. \& TURNER, M.D. -1988- Calochlaena, a new genus of Dicksonioid ferns. Amer. Fern Journ., 78: 86-95. fig. 1-14.

WICKENS, G.E. -1976- The flora of Jebel Marra (Sudan Republic) and its geographical affinities. Kew.Bull. Addit. Ser. vol. V: pp. 1-368. fig. 1-34. maps 1-208.

WOLFE, J.A. -1978- A palaeobotanical interpretation of the tertiary climats in the Northern Hemisphere. Amer. Scientist. 66: 694-703. fig. 1-7.

ZOHARY, M. -1962- Plant life of Palestine Israel and Jordan. New York (Ronald).

\section{Pubblicazioni consultate, ma non citate nel testo, concernenti la paleogeografia.}

ABBATE, E., V. BORTOLOTTI, M. CONTI, M. MARCUCCI, G. PRINCIPI, P, PASSERINI \& B. TREVES -1986- Apennines and Alps ophiolites and the evolution of the western Tethys, Mem. Soc. Geol. Ital. 31: 23-44. fig. 1-18.

ANGELIER, J., N. LYBERIS, X. LEPICHON \& E. BARRIER -1986- The tectonic development of the Hellenic arc and the sea of Crete: a synthesis. Tectonophysics 86: 159-196. fig. 1-14.

AXELROD, D.I. -1970- Mesozoic paleogeography and early Angioperm history. Bot. Rev., 36: 277-319. fig. 1-6.

AZZAROLI, A. -1983-Biogeografia dei mammiferi della Sardegna. Lav, Soc. Ital. Biogeogr. Ser. 2. 8: 35-52. fig. 1. ('1980').

BECK, R.H. \& P. LEHNER -1974- Oceans, new frontiẹr in exploration. Amer. Assoc. Petrol. Geol. Bull., 58: 376-395. fig. 1-25. 
BERGGREN, W.A. \& J.A. VAN COUVERING -1974- The late Neogene. Biostratigraphy, geochronology and paleoclimatology of the last 15 milion years in marine and continental sequences. Palaeogeogr. Palaeoclim. Palaeoecol. 16(1-2): 1-216. fig. 1-14.

BOCCALETTI, M. -1979- Mesogea, Mesoparatethys, Mediterranean and Paratethys: their possible relations with Tethys Ocean development. Ophioliti, 4: 83-96. fig. 1(A-F).

BOCCALETTI, M. \& G. GUAZZONE -1972- Gli archi appenninici, il mar Ligure ed il Tirreno nel quadro della tettonica dei bacini marginali retro-arco. Mem. Soc. Geol. Ital., 11: 201-216. fig. 1-6.

BOCCALETTI, M. \& G. GUAZZONE -1974- Plate tectonics in the Mediterranean region. in Coy Squyres (ed.). Geology of Italy. Tripoli (Petrol. Expl. Soc. Lybia) pp. 1-23. fig. 1-6.

BOCCALETTI, M., G. GUAZZONE \& P. MANETTI -1974- Evoluzione paleogeografica e geodinamica del Mediterraneo. I bacini marginali. Mem. Soc. Geol.Ital. 13 (Suppl. 2) : 137. fig. 1-29.

BOCCALETTI, M., D. COSENTINO, G. DEIANA, R. GELATI, F. LENTINI, F. MASSARI, G. MORATTI, T. PESCATORE, A. PORCU, G. RICCHETTI, F. RICCI LUCCHI \& L. TORTORICI -1987- Neogene dynamics of the Peri-tyrrhenian area in an ensialic context: paleogeographic reconstruction. Mayar Állami Földt. Intéz. Évk. 70: 307-321. fig. 1-9.

BOCCALETTI, M., N. CIARANFI, D. COSENTINO, G. DEIANA, R. GELATI, F. LENTINI, F. MASSARI, G. MORATTI, T. PESCATORE, F. RICCI LUCCHI \& L. TORTORICI 1990- Palinspastic restoration and paleogeographic reconstruction of the Peri-Tyrrhenian area during the Neogene. Palaegeogr. Palaeoclimatol. Palaeoecol., 77: 41-50. fig. 1. tav. 1-7.

DE BRUIJN, H. -1973-Analysis of the data bearing upon the correlation of the Messinian with the succession of land mammals. in Drooger, C.W. (ed.), 1973. pp. 260-262.

DERCOURT, J., L.P. ZONENSHAIN, L.E.RICOU \& AL.-1986- Geological evolution of the Tethys belt from the Atlantic to the Pamirs since the Lias. Tectonophysics, 123: 241-315. fig. 1-4. tav. (maps) 1-10.

DEWEY, J.F., W.C. PITMAN III, W.B.F.RYAN \& J. BONNIN -1973- Plate Tectonics and the evolution of the Alpine System. Geol. Soc. Amer. Bull., 84: 3137-3180. fig. 1-19.

DIETZ, R.S. \& J.C. HOLDEN -1971- La scissione della Pangea. Le Scienze (Sci. Amer.), 6(29): 156-167. fig. 10.

DINOCERA, S., F. ORTOLANI \& M. TORRE-1976- La tettonica messiniana nell'evoluzione della Catena Appenninica. Il Messiniano nel quadro evolutivo del Mediterraneo. pp. 2947. fig. 1-5. C.N.R. (Programma Geodinamica).

DROOGER, C.W. (ed.) - 1973- Messinian events in the Mediterranean. Geodinamics Scientific Report No. 7. Amsterdam (North Holland Co.).

ELTER, P. \& G. GIGLIA - 1976- Il Mediterraneo e le Catene alpine. Il Messiniano nel quadro evolutivo del Mediterraneo. pp. 3-28. fig. 3. C.N.R. (Programma Geodinamica).

HSÜ, K.J. -1973- When the Mediterranean dried up. Sci. Amer. 227: 27-36. fig. 7.

HSÜ, K.J. - 1973- Quando il Mediterraneo si disseccò. Le Scienze (Sci. Amer.), 10(56): 19, 22 29. fig. 7.

LEPICHON, X., S.S. AUGUSTITHIS \& J. MASCLE (eds.) -1982-Geodinamics of the Hellenic arc and trench. Tectonophysics, 86: 1-304.

OLIVET, J.L., J. BONNIN, P. BEUZART \& J.M. AURIZENDE -1984- Cinématique de l'Atlantique nord et central. Centre National pour l'exploitation des Océans. Rapports Sci. Techn. № 54. Vol. 1: 1-108; fig. 1-30. vol. 2: cartes 1-4.

RAVEN, P.H. \& D.I. AXELROD -1974- Angiosperm biogeography and past continental movements. Ann. Missouri Bot. Gard. 61: 539-673. fig. 1-5. 
RUGGIERI, G. -1967- The Miocene and later evolution of the Mediterranean Sea. in Adams, C.G. \& Ager, D.V. (eds.). Aspects of Tetyan Biogeography. (Syst. Assoc. Publ. No. 7). pp. 283-290. fig. 2.

SELLI, R. -1973- Il Mediterraneo nel Miocene superiore: un mare sovrasalato, in Hsü, K.J., 1973. pp. 20-21. fig.1.

SNELLING, N.J. (ed.) -1985- The chronology of the geological records. Geolog. Soc. Memoir 10: $1-343$.

SNELLING, N.J. -1985- An interim time-scale, in Snelling, N.J. (ed.)., 1985: pp. 261-265. fig. $1-3$.

WOLFE, J.A. -1975- Some aspects of plant geography of the Northern Hemisphere during the late Cretaceous and Tertiary. Ann. Missouri Bot. Gard. 62: 264-279. fig. 1-4.

ZIEGLER, P.A. -1988-Evolution of the Arctic-North Atlantic and the Western Tethys. Amer. Assoc. Petrol. Geol. Mem. 43: I-VII, 1-198. fig. 1-80. tav. 1-30.

(Melilla, Septiembre de 1989)

Dirección del autor: Via Cantagrilli 1- 50020 Montagnana Val di Pesa (Firenze). Italia. 